OPEN ACCESS

Edited by:

Maria Antonietta Ciardiello,

Italian National Research Council, Italy

Reviewed by:

Jeffrey Michael Wilson,

University of Virginia, United States

Simon Blank

Technical University of Munich and

Helmholtz Center Munich, Germany

*Correspondence:

Geoffrey A. Mueller

geoffrey.mueller@nih.gov

Specialty section

This article was submitted to Allergens,

a section of the journal

Frontiers in Allergy

Received: 02 September 2021 Accepted: 04 October 2021

Published: 28 October 2021

Citation:

Foo ACY and Mueller GA (2021) Abundance and Stability as Common

Properties of Allergens.

Front. Allergy 2:769728.

doi: $10.3389 /$ falgy.2021.769728

\section{Abundance and Stability as Common Properties of Allergens}

\author{
Alexander C. Y. Foo and Geoffrey A. Mueller* \\ Genome Integrity and Structural Biology Laboratory, National Institute of Environmental Health Sciences, Durham, NC, \\ United States
}

There have been many attempts to identify common biophysical properties which differentiate allergens from their non-immunogenic counterparts. This review will focus on recent studies which examine two such factors: abundance and stability. Anecdotal accounts have speculated that the elevated abundance of potential allergens would increase the likelihood of human exposure and thus the probability of sensitization. Similarly, the stability of potential allergens dictates its ability to remain a viable immunogen during the transfer from the source to humans. This stability could also increase the resilience of potential allergens to both gastric and endosomal degradation, further skewing the immune system toward allergy. Statistical analyses confirm both abundance and stability as common properties of allergens, while epidemiological surveys show a correlation between exposure levels (abundance) and allergic disease. Additional studies show that changes in protein stability can predictably alter gastric/endosomal processing and immunogenicity, providing a mechanistic link between stability and allergenicity. However, notable exceptions exist to both hypotheses which highlight the multifaceted nature of immunological sensitization, and further inform our understanding of some of these other factors and their contribution to allergic disease.

Keywords: allergens, stability, abundance, exposome, allergenicity

\section{INTRODUCTION}

Allergic diseases, characterized by a Th2 immune response to typically innocuous environmental antigens, are one of the most common health disorders worldwide with a prevalence of 1-20\% depending on the region (1). Respiratory allergies are often comorbid with asthma, hypertension, and other respiratory disorders while food, drug, and venom allergies can result in life-threatening anaphylactic reactions in up to $5 \%$ of the American population, highlighting the burden of allergic disease on human health and wellness (1-4). Despite the size of the exposome, it has been repeatedly noticed that allergens which are capable of eliciting a Th2 allergic response are generally distributed across relatively few protein families, suggesting the presence of specific biophysical properties which promote sensitization (5). Understanding the factors which differentiate allergens and nonallergens can provide valuable insight into the mechanism of allergic sensitization, with potential implications for the design of novel immunotherapies and mitigation strategies.

Allergic sensitization is a multifaceted process, a comprehensive discussion of which is beyond the scope of a single work. Instead, this review will focus on recent work examining two frequently-cited factors: allergen stability and abundance. Intuitively, the link between abundance, stability, and allergenicity appears straightforward with higher 
abundance correlating with an increased risk of exposure. Similarly, higher stability increases the length of time allergens will persist in the environment, further increasing the likelihood of exposure. However, these seemingly obvious concepts are surprisingly controversial. For example, many studies have attempted to correlate allergen exposure levels with sensitization. However, there remain uncertainties concerning the most relevant routes of exposure, and dominant reservoirs of allergenic material (6). Similarly, many longitudinal studies have failed to demonstrate predictable dose response relationships (6). Likewise, a systematic investigation into the role of stability in allergen exposure is an equally daunting endeavor with variable definitions of protein stability. For instance, aeroallergens must endure dehydration, oxidative exposure, and UV radiation, while in the context of food science one must consider the effects of gastric digestion and food preparation. Some fields may eschew both definitions altogether and focus instead on a more biophysical approach centered on thermal/chemical denaturation or conformational stability. Further complicating the conversation is the need to consider the role of stability and abundance in multiple contexts. For example, recent work suggests that food allergy to peanuts is the result of co-exposure to the skin and intestine where different measures of exposure and stability may apply (7).

It is worth reminding the reader that exposure to potential allergens is only the first step in the sensitization process. From here, potential allergens must be processed, and the resulting antigenic fragments presented to the immune system for recognition. The intensity, duration, and timing of this presentation are also important factors $(8,9)$. The prevalence of allergens and their resistance to both gastric and endosomal proteolysis could alter the kinetics of this process, providing an additional mechanism through which stability and abundance influence allergenicity while offering insights into the sensitization pathway $(10,11)$. This review will highlight recent literature examining the role of antigen stability and abundance in the sensitization process, along with several notable exceptions to this trend. The biochemical and biophysical mechanisms which mediate this interaction will be examined, along with their implications for human health and disease.

\section{ABUNDANCE AND STABILITY AS IMPORTANT CHARACTERISTICS OF ALLERGENS}

The correlation between abundance and allergenicity is intuitively easy to understand, but significantly harder to verify in a rigorous manner. Circumstantial evidence for such a relationship can be found in the observation that food allergens such as Pen a 1 (shrimp), and Ara h 1 and Ara h 2 (peanut) comprise a significant portion (up to $20 \%$ ) of the total protein that humans consume when eating shrimp and peanuts (12-14). Similar results have been reported for both indoor and outdoor aeroallergen sources such as cockroach frass (Bla g 1, 18\% total protein), Timothy grass pollen ( $\mathrm{Phl} \mathrm{p} \mathrm{5,6.4 \%} \mathrm{total} \mathrm{protein),}$ and house dust mite extracts (Der p 1, 33\% total protein) (15-17). Epidemiological studies provide further evidence for an empirical link between abundance and allergenicity. For example, comparing the levels of cockroach allergen in house dust samples from households with cockroach-allergic and non-allergic children reveals a strong linear correlation between sensitization and allergen (Bla g 1 and Bla g 2) content, with some studies showing a sensitization rate upwards of $80 \%$ in households with the highest exposure levels $(18,19)$. Similar results have been reported for dust-mite allergen exposure and sensitization, though no dose-response relationships for other indoor allergens such as mold, dog, or cat were identified (20-22). The methodological challenges associated with assessing environmental allergen exposure could in part contribute to these inconsistent results. For instance, airborne allergens are extremely prevalent in the community, and can be found in public spaces such as schools, offices, and daycares at levels sufficient to promote sensitization independent of household exposure (23-26). Additionally, the presence of allergic symptoms or a familial predisposition to indoor allergies could encourage households to actively reduce exposure through avoidance or mitigation strategies, yielding a spurious inverse dose-response correlation among some study subjects (27). Finally, most environmental exposure studies fail to report the prevalence of allergens relative to their non-allergic counterparts. One should note that the motivation of these studies was to understand the environmental factors which contribute to allergenicity; a goal in which they have succeeded admirably. However, this limitation hinders the efforts of our present review to assess abundance as a biophysical determinant of allergenicity in an empirical manner.

Two recent studies have addressed this major research gap in the field. These studies used RNA-Seq to quantify the transcription levels of 39 allergens and $>1,000$ non-allergenic proteins from cockroaches, dust mites, and tree, weed, and grass pollens; providing an empirical measurement of abundance within their respective allergen sources $(28,29)$. While the abundance of potential allergens contributes to the likelihood of human exposure, the ability to resist environmental degradation also plays a key role. In recognition of this, the authors employed chemical denaturants coupled with high-throughput massspectrometry techniques to simultaneously assess the biophysical stability of their protein samples. The large sample sizes employed in these studies allowed the authors to demonstrate with a high degree of statistical certainty that allergens were generally both more stable and more abundant than their nonallergic counterparts. Similar analyses have been carried out on food allergens, though given their route of exposure a greater emphasis has been placed on their ability to resist gastric digestion (30-32). While less extensive than their aeroallergen counterparts, these works do suggest that food allergens are indeed more resilient than their non-allergenic counterparts.

It should be noted that the global stability of a protein may not reflect that of its immunogenic fragments. For instance, the peanut allergen Ara h 3 is broken down when subjected to simulated gastric digestion (33). However, IgE-reactive regions remain intact, allowing it to retain its sensitizing potential 


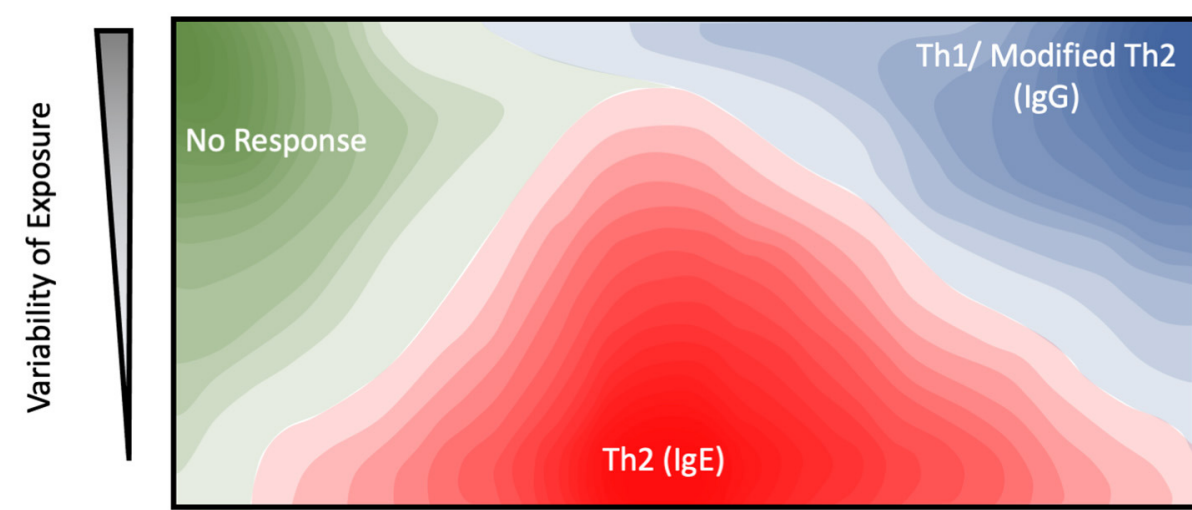

Level of Exposure

FIGURE 1 | Contour plot depicting the proposed relationship between the level of exposure, variability of exposure, and immune response for potential environmental allergens.

(33). Likewise, the peanut allergens Ara h 2 and Ara h 6 survive digestion, and remarkably can be detected in breast milk, remaining immunologically intact after lactation $(34,35)$. A different process was noted for the allergens Ber e 1 (Brazil nut), Jug r 2 (Walnut), and Ara h 1 (Peanut). In situ proteolytic cleavage results in the release of a small vicilin-buried peptide (or peptides), which possess their own immunogenic activity independent of the vicilin allergen (36-38). Even with this consideration of immunogenic fragmentation, the correlation between exposure, and allergenicity is far from complete. A closer examination of some of these exceptions provides invaluable insight into the sensitization process.

\section{ANOMALOUS DOSE-RESPONSE CURVES PROVIDE INSIGHT INTO THE MECHANISMS OF ALLERGIC SENSITIZATION}

While abundance generally correlates with allergenicity, other factors such as the timing or duration of exposure also need to be considered. Exposure to occupational allergens is often consistent and well-defined, providing a viable platform for exploring this perspective. Indeed, a study examining the correlation between mouse allergy and occupational exposure among animal facility workers revealed a parabolic relationship, with moderate (1 $\mathrm{ng} / \mathrm{m}^{3}$ ) levels of atmospheric Mus $\mathrm{m} 1$ resulting in a 10 -fold increase in the odds ratio for sensitization, while exposure levels either above or below this level reduced this risk to near-baseline levels (39). Interestingly, the authors observed that the dayto-day variability of exposure levels played an equal, if not more important role with consistent, low to moderate dosages being required for allergic sensitization while high variability and high-dosage regimes resulted in a reduction in both serum IgE and allergic symptoms. This dovetails well with studies examining household sensitization, in which exposure to mouse allergen levels below this $1 \mathrm{ng} / \mathrm{m}^{3}$ threshold yield a linear doseresponse curve (40). Another study examining occupational allergies among University personnel in Brazil yielded similar results. Here, the concentration or intensity of mouse or rat allergen within the work environment was not a significant risk factor for sensitization (41). Instead, the duration of exposure and job category (e.g., technician vs. student) emerged as major determinants of allergenicity. While the role of variability was not specifically examined in these studies, the results are consistent with the model shown in Figure 1 in which the time-course of presentation plays an equal, if not more important role than mouse allergen concentration or exposure intensity.

Similar results have been observed in beekeepers, whose occupational exposure to the bee allergen Api m 1 is highly intermittent $(42,43)$. Under this highly-variable exposure regime, allergic sensitization and serum IgE levels were inversely correlated with average dosage level, as measured by the number of stings received. In one paper, $\sim 80 \%$ of keepers with the lowest exposure levels ( $<25$ stings per year) displayed sensitization against Api m 1 (44). This figure drops drastically to $35 \%$ for keepers who received 25-200 stings per year, while no systemic response was observed at all among those which received the highest dosages ( $>200$ stings a year) (42-45). These results suggest a model in which high-intensity and variability exposure regime elicit a protective effect, while moderate, sustained dosages are more likely to generate an allergic response (Figure 1).

A few comments on the mechanisms of allergic tolerance are in order before returning to the central theme of abundance and exposure. In the studies mentioned above, tolerance to the bee venom Api $\mathrm{m} 1$ was driven by the conversion of both Th1 and Th2 cells into IL-10 secreting $\operatorname{Tr} 1$ cells, giving rise to what has been termed a modified Th2 response (44, 46-48). In this model, IL-4 induces B-cell activation and antibody production, similar to 


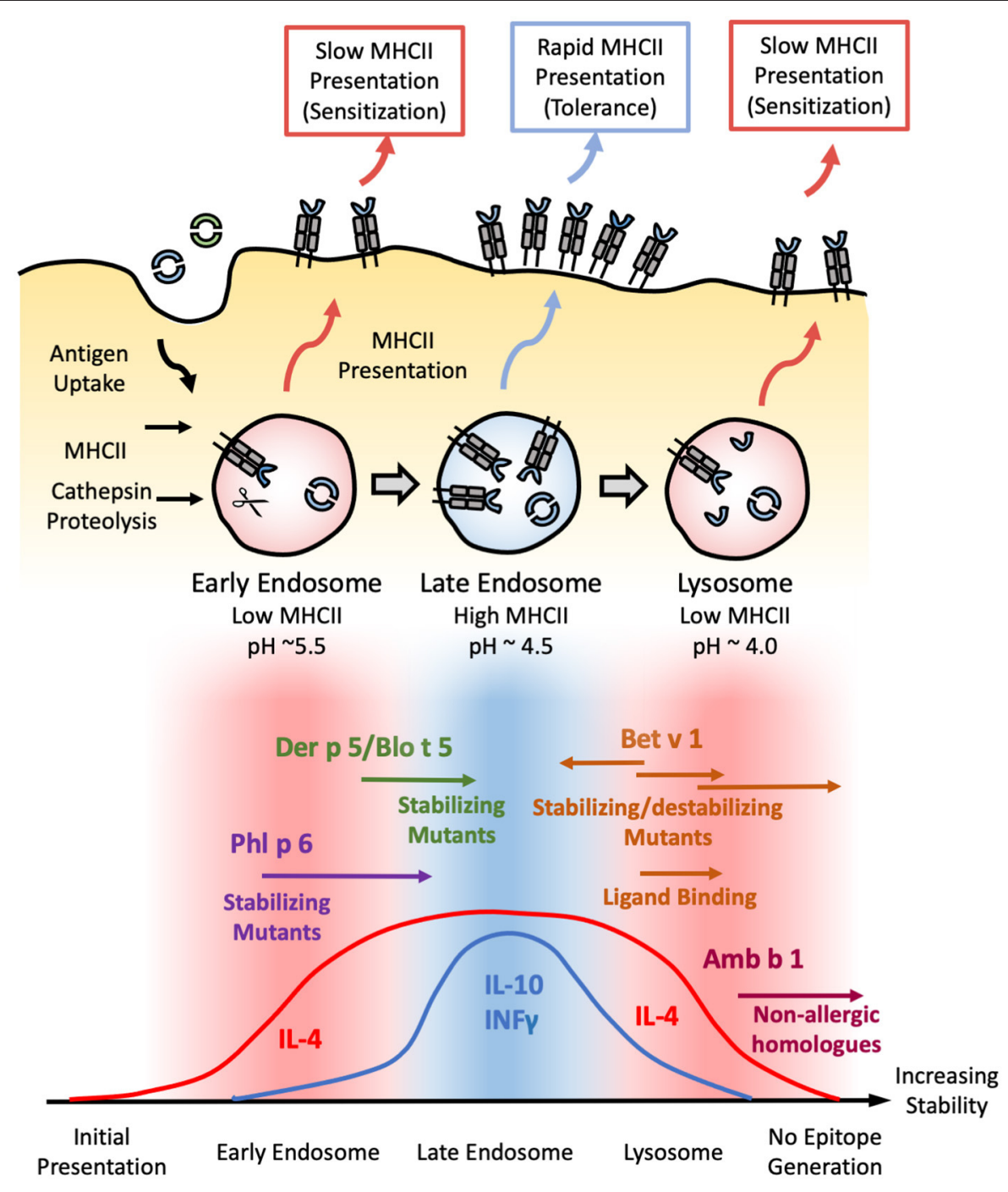

Timing of Epitope Generation

FIGURE 2 | Model correlating allergen stability against endosomal degradation and immunogenicity. (Top) Schematic illustrating the process of endosomal degradation and epitope presentation. Antigens are internalized into the endosomes of antigen presenting cells, where they are subjected to cathepsin proteolysis under reducing and increasingly acidic conditions. The resulting epitope fragments are loaded onto MHCll molecules for presentation and T-cell recognition. MHCII loading is most efficient in the late endosome. As such, epitopes generated in this stage are more likely to generate a protective Th1 or modified Th2 response defined by the presence of both IL-4/IL-10 and/or INF (tolerance). Conversely, epitopes generated in the early endosome or lysosome are more likely to yield an IL-4-dominated Th2 response (sensitization) due to the scarcity of MHCII in these compartments, resulting in a more gradual, sustained, yet low intensity mode of presentation. (Bottom) Based on this model, exposure to proteins with an intermediate stability against endosomal degradation are more likely to induce tolerance (blue), while proteins which deviate from this medium in either direction are more liable to develop allergic sensitization (red). This is illustrated with Phl $p 6$ and Der $p$ 5/Blo t 5; and Bet v 1 and Amb a 1 as representative high and low-stability allergens respectively. Stabilizing mutants shift the former into the intermediate-stability regime, resulting in a tolerogenic response. In contrast, enhancing the stability of the latter via mutations, chemical modification, or ligand binding enhances their sensitizing potential, while destabilizing mutants of Bet $v 1$ have the opposite effect. Note that antigens which occupy either extreme of this scale are expected to elicit no immune response due to the lack of epitope generation and/or MHCIl loading, as illustrated by the low immunogenicity of extremely stabilized variants of Amb b 1 or Bet v 1.

the standard Th2 response. However, the simultaneous presence of IL-10 stimulates B-cell class-switching from IgE antibody production to $\mathrm{IgG}_{4}$, while depletion of Th2 cells also reduces the secretion of IL-4 and other pro-inflammatory cytokines (4951). While some Th1-Tr1 conversion was observed, the authors noted that $\operatorname{Tr} 1$ class switching was mediated primarily through histamine receptor 2 (HR2) (48). HR2 acts primarily to suppress Th2 cell proliferation and cytokine secretion. Like its Th1associated subclasses $\left(\operatorname{IgG}_{1-3}\right), \operatorname{IgG}_{4}$ is generally viewed as a protective antibody which has been shown to block IgE binding 
and cross-linking against a range of allergens $(46,52)$, though some studies challenge its protective effects (53). Nonetheless, both IL-10 production and IgG $_{4}$ class-switching remain strongly associated with a reduction in serum IgE and allergic symptoms, giving rise to the protective effect observed among beekeepers (48). Similar class-switching has been observed in laboratory workers in mice and rat facilities, suggesting that this modified Th2 response contributes to allergic tolerance in a wide range of environmental allergens $(39,52,54)$. Here, allergic tolerance was correlated to both $\operatorname{IgG}_{4}$ and $\operatorname{IgG}_{1-3}$. While the latter was not found to be statistically significant, it is consistent with other studies in which the protective effect of immunotherapy treatments is mediated by a plurality of IgG isoforms suggesting both the classic Th1 and modified Th2 response can contribute to tolerance (55-58). Despite its protective effects, the modified $\mathrm{Th} 2 / \mathrm{IgG}_{4}$ response is dependent on initial B-cell activation by IL-4. As such, the kinetics of IL-10 expression are critical to avoid terminal Th2 differentiation, with in-vitro experiments suggesting a $72 \mathrm{~h}$ narrow window in which $\mathrm{IgG}_{4}$ class-switching must occur (59). Additionally, IL-10 production by dendritic cells is extremely transient, being detected only within 24$72 \mathrm{~h}$ of antigen exposure (60). A frequent, high-intensity exposure regime potentially increases the probability that the kinetics of IL-10 production coincides with the narrow window required for modified Th2 response and $\mathrm{IgG}_{4}$ class-switching, promoting allergic tolerance against occupational allergens under these conditions.

While occupational allergen exposure levels and timing can be easily defined, the same generally cannot be said for household allergens, hindering efforts to determine whether the latter follow the same dose-response model as shown in Figure 1. One interesting approach to overcome this challenge is embodied by the work of Woodcock et al. in which they actively altered the household environment through the use of allergen mitigation strategies, and assessed their effect on allergic sensitization and serum IgE levels (61). These interventions include the use of allergen-impermeable bed covers, vinyl flooring materials and a rigorous laundry schedule among others, and were effective at significantly reducing the levels of Der p 1, Fel d 1 (cat) and Can f 1 (dog) allergens $\sim 2$ to 3 -fold relative to a control group. The treatment group displayed a significant increase in serum IgE against Der $\mathrm{p} 1$, but not Fel d 1 or Can $\mathrm{f} 1$ despite their airborne allergen levels being suppressed to the same degree. One potential explanation stems from the differences in exposure patterns. In a household setting, mite and cockroach allergens are found within relatively large particles $(>10 \mu \mathrm{m})$. Due to their size, the majority of mite allergens remain confined to their reservoirs until physically disturbed $(62,63)$. In practice, this results in relatively low exposure to ambient airborne mite allergens, punctuated by transient periods of high exposure as the resting reservoirs are disturbed. For example, time-based measurements of personal mite allergen exposure indicate that initial entry into the bed yielded an intense $>100$-fold increase in airborne Der $\mathrm{p} 1$ concentrations (64). However, allergen levels quickly returned to their resting-phase concentrations within 20 minutes following disruption $(47,63)$, ensuring that the sleep phase accounted for a small minority $(\sim 10 \%)$ of total exposure despite the bed being a major allergen reservoir $(23,24)$. Similarly, agitation of carpets and other allergen reservoirs during daytime activity such as walking or bedmaking results in the resuspension of a large number of allergen-containing particles, which rapidly settle down and dissipate in under an hour $(65,66)$. The intervention levels introduced by Woodcock et al. eliminate these transient spikes, potentially contributing to the increased sensitization. In contrast a greater proportion of $\mathrm{dog}$ and cat allergens are carried by smaller $(<5 \mu \mathrm{m})$ particles which remain airborne for significantly longer (2-14 days) following disruption, resulting in a much more consistent exposure pattern regardless of human intervention $(64,67,68)$. An important assumption in these studies is that the majority of the allergen exposure occurs in the home. This has been challenged by studies using personal air samplers (24), and studies of allergen prevalence in schools (69). Despite these many concerns, it is notable that Fel d 1, Can $\mathrm{f} 1$, and Der p 1 share similar non-linear dose-response curves, with home exposures above $20 \mu \mathrm{g}$ of allergen per gram of house dust being associated with reduced allergenicity and an increased IgG response (70-73). This suggests that the model described in Figure 1 can be broadly applied to both workplace and environmental allergens.

It has been consistently observed that the prevalence of both inhalation and food allergies is significantly lower in rural populations when compared to their urban counterparts, providing an additional avenue through which the effect of household environment on allergic sensitization can be examined (74-76). As with the Woodcock study, a significant reduction in mite sensitization and serum IgE was observed among children living on farms despite experiencing higher exposure levels within their homes than their more urban counterparts (77). One potential explanation would be that the former spend significant portions of their day outside their homes, resulting in a higher variability in mite allergen exposure as they transition from the outdoor to indoor environment. This is in contrast to the latter which spend the majority of their waking hours indoors where they receive a consistent, if lower intensity dosage of mite allergens. This inverse correlation between indoor and animal allergen exposure and sensitization among rural and agricultural communities has been widely reported $(78,79)$, and provides a valuable tool for dissecting the role of allergen exposure in sensitization. However, it is important to remember that other environmental differences could also contribute to this urban/rural divide. For instance, a comparison of Amish and Hutterite farming communities points to endotoxin exposure as a key determinant of sensitization: while both populations share numerous genetic and cultural similarities, the more traditional agricultural practices of the former result in significantly higher exposure to levels of airborne bacterial endotoxins and lower levels of indoor allergen sensitization $(80,81)$. The higher prevalence of endotoxin found in rural/farm dwellings relative to their urban counterparts could play a similar role (78). While a comprehensive assessment of the environmental determinants of allergy is beyond the scope of this review, suffice it to say that allergic sensitization is a multifaceted process in which the abundance of the potential antigen and the timing of exposure are important, but often not the sole contributors. 


\section{ANTIGEN PRESENTATION KINETICS AND STABILITY INFLUENCE ALLERGIC SENSITIZATION}

A mechanistic basis for this unusual dose-response relationship may be attributed to the underlying process of T-cell activation. To be recognized as an allergen, exogenous antigens must first be internalized into the endosome of an antigen presenting cell (APC) such as the dendritic cells discussed above. Internalized antigens are then subjected to endosomal degradation, where they are exposed to cathepsin proteases (Figure 2) under increasingly acidic and reducing conditions. The resulting peptide fragments are loaded onto the class two major histocompatibility complex (MHCII) and presented on the cell surface for recognition by T-cell receptors (TCR). The kinetics of MHCII-antigen presentation and TCR binding can influence Tcell differentiation. High, but transient concentrations of MHCIIpeptide complexes stimulate the production of tolerogenic cytokines and suppression of IL-4 consistent with a Th1 or modified Th2 response. Conversely, lower, but more persistent presentation skews the immune system toward an IL-4dominated Th2 response $(8,82,83)$. As one might expect, the abundance and exposure regime of an allergen directly contributes to the kinetics and intensity of MHCII presentation, with large, acute exposures resulting in allergic tolerance as shown in beekeepers and mouse facility workers as discussed in the previous section (84). However, the biophysical stability of an allergen and its ability to resist endosomal degradation can also influence MHCII-presentation kinetics. This was examined using the major birch allergen Bet $\mathrm{v} 1$. Bet $\mathrm{v} 1$ was among the least stable proteins tested by Cabrera et al. (29). However, this observation fails to consider the fact that Bet $\mathrm{v} 1$ in its natural allergen source exists as a complex mixture of different isoforms, each with different biophysical properties (85). For example, Bet $\mathrm{v} 1 \mathrm{a}$ (Bet $\mathrm{v}$ 1.0101) is significantly more stable, with noticeably reduced conformational flexibility than Bet v 1d (1.0102) as assessed using solution-NMR (86). The increased stability of the former increases its resilience to Cathepsin S proteolysis, resulting in slow MHCII loading and associated Th2 polarization, while its less stable counterpart is associated with a protective $\operatorname{IgG}$ response $(85,87,88)$. Similarly, nitration of Bet $\mathrm{v} 1$-mimicking the effect of air pollution in industrialized nations-resulted in the formation of higherorder oligomers. The resulting complexes displayed enhanced resistance to endosomal degradation, and were more liable to generate a Th2 response than their unmodified counterparts (89). This trend is not only limited to Bet v 1. For instance, loss of conserved disulfide bonds severely compromised protein structure and stability of Pru p 3 (peach) and Art v 1 (Mugwort), reducing allergenicity $(90,91)$. A more systematic approach is presented by Ohkuri et al. Here, they created a series of $\mathrm{Phl} \mathrm{p}$ 7 and hen egg lysozyme (HEL) variants with varying degrees of biophysical stability, and quantitatively assessed their ability to elicit a protective IgG response. Their results reveal a surprisingly strong inverse linear correlation between the $\Delta G$ of unfolding and IgG production (92). Applying a linear extrapolation to their data yields a $\Delta \mathrm{G}$ value of $\sim 22 \mathrm{kcal} / \mathrm{mol}$, above which allergic sensitization (i.e., no protective IgG response) can be expected (92). The folding energy of globular proteins tend to lie in the $\sim 5-20 \mathrm{kcal} / \mathrm{mol}$ range indicating that allergens tend to be more stable than their non-allergenic counterparts $(93,94)$.

The majority of MHCII loading occurs at the late endosome ( $\mathrm{pH} \sim 4.5-5.5)$, while early endosome $(\mathrm{pH} \sim 6)$ and terminal lysosomes ( $\mathrm{pH} \sim 4.0-4.5$ ) are poor in MHC II molecules (95), suggesting that the $\mathrm{pH}$ dependence of fold stability must also be considered. This is illustrated by a study carried out by Machado et al. examining the immunogenicity of various stabilized Bet v 1 mutants. The mutant which generated the strongest IgE response was found to be extremely stable at $\mathrm{pH}$ $<5$, but was susceptible to limited proteolysis under the more acidic conditions found within the late endosome and terminal endosome (96). Mutants which inhibited proteolysis under all conditions were markedly less immunogenic, suggesting an upper limit beyond which further enhancements reduce immunogenicity through suppressing MHCII presentation (96). Such a conjecture is supported by subsequent studies on the pectate lyase $\mathrm{C}$ family, in which non-allergic members were found to be significantly more resistant to endosomal proteolysis than Amb a 1: the major allergen from ragweed (97). These results allow us to build a model in which proteins with intermediate stability elicit a protective IgG response, with the majority of their antigenic fragments being released in the late endosomes for rapid MHCII loading and presentation. In contrast, proteins which are able to survive into the lysosome before succumbing to proteolysis stimulate an allergic IgE response due to the scarcity of MHCII molecules, while extremely stabilized proteins fail to yield any appreciable MHCII loading even after prolonged digestion (Figure 2).

From this conjecture, one could extrapolate that proteins which deviate in the other direction (i.e., less stable) can also trigger a Th2 response due to the scarcity of MHCII molecules in the early endosome, where the majority of antigenic fragments are produced. This could explain the allergenicity of Phl p 6 and Der p 5-neither of which displayed a significant enhancement in biophysical stability relative to their non-allergenic counterparts (29). Stabilizing the Phl p 6-fold resulted in a shift toward a Th1/modified Th2 response, while destabilizing mutants had the opposite effect (11). Similarly, a stabilized N-terminal truncated form of the Der p 5 homolog Blo t 5 reduced IgE production without altering the repertoire of $\mathrm{T}$-cell epitopes generated (98), confirming that both allergen families lie in the "low stability" island of Th2 polarization. Stabilizing/destabilizing mutants have been shown to elicit similar effects in both dust mite Der p 2 and hen egg lysozyme $(99,100)$. Thus, while fold stability is a major determinant of allergenicity, $\mathrm{pH}$ stability must be carefully considered within the context of the endosomal degradation process.

MHCII is synthesized with an invariant chain (Ii) which is cleaved upon maturation, leaving a short "placeholder" peptide (CLIP) bound into the MHCII epitope pocket. In order to be loaded onto MHCII, prospective epitopes must first displace the bound CLIP peptide: a process which is aided by the accessory molecules HLA-DM (DM) and HLA-DO (DO), which catalyzes the peptide exchange process (101). Thus, the ability of 


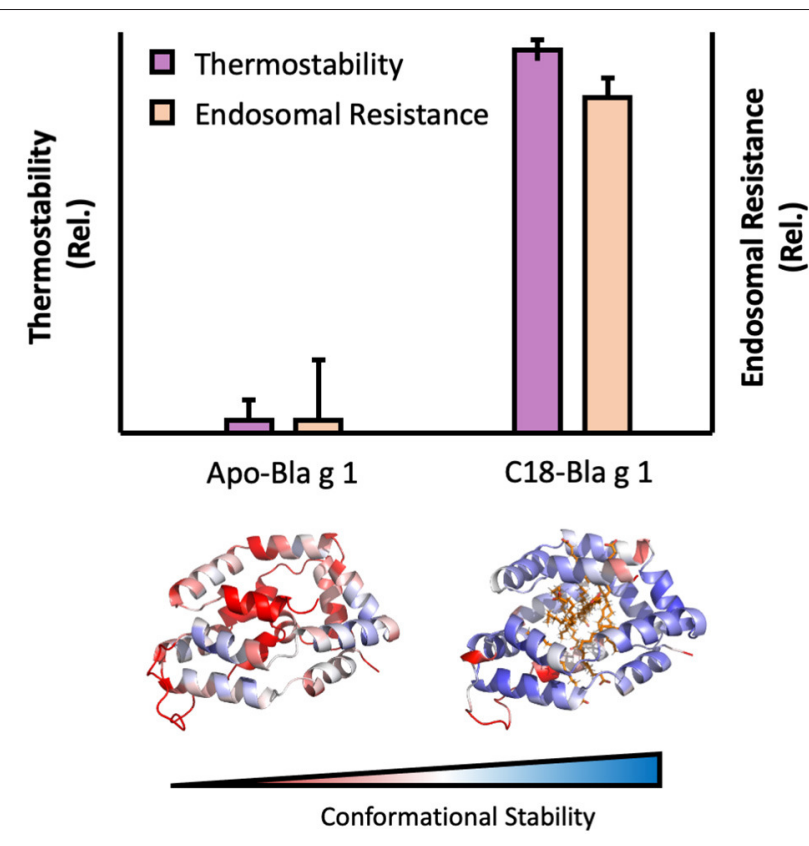

FIGURE 3 | Image showing the influence of ligand binding on Bla g 1 stability. Thermal stability and endosomal processing (Top) and backbone $(\mathrm{C} \alpha)$ conformational stability (Bottom) of Bla $\mathrm{g} 1$ in the Apo form, or fully loaded with $\mathrm{C} 18$ fatty acid ligands. Data replicated from Foo et al. and presented under the Creative Commons CC BY License (122).

prospective epitopes to bind DO/DM and displace CLIP play a key role in immunogenicity (102-104). This is illustrated in a recent study in which the CLIP sequence from antigen presenting cells was exchanged for antigenic sequences from Bet $\mathrm{v} 1$, Art v 1, and Cry j 2 (Japanese cedar). This significantly enhances the apparent affinity of these peptides for MHCII, greatly boosting antigen presentation and T-cell activation by these recombinant APC's $(105,106)$. Likewise, conjugating the cat allergen Fel d 1 to the Ii sequence significantly enhanced MHCII presentation, promoting a modified $\mathrm{Th} 2 / \mathrm{IgG}_{4}$ response and allergen tolerance in human subjects during phase I/IIa clinical trials (107). Similarly, studies examining the therapeutic potential of dendritic cells modified to endogenously express mite allergens showed skewing toward a Th1 and modified Th2 response, though the specific mechanism through which this protective effect was induced was not directly assessed (108). Conversely, the presence of other DM/DO/MHCII ligands in the endosomal milieu could competitively inhibit MHCII loading (106). Such an interaction might account for the increased prevalence of mite sensitization among patients who are co-exposed to other allergens, though this conjecture has yet to be demonstrated on the molecular level (109). Further complicating this model is the observation that binding of antigenic fragments to DM/DO and MHCII shields them from further proteolysis (102-104). Thus, while the model shown in Figure 2 provides a biophysical basis for the role of protein stability in MHCII loading and allergenicity, there are always other factors to consider.

Even with this expanded understanding it is important to remember that exceptions will always exist. For instance, a survey of tropomyosin allergens from both food (Pen $\mathrm{m} 1$, Shrimp; Ani s 3, fish parasite) and environmental (Der p 10, dust mite; Bla g 7, cockroach) sources revealed significant variation in both thermodynamic stability and endosomal degradation kinetics (110). However, neither measure of stability was found to correlate with allergenicity. A separate survey of 15 allergens and non-allergens found that resistance to gastric, but not endosomal degradation predicted allergenicity (111). However, a pairwise comparison of LTP, albumin, tropomyosin, collagen, and parvalbumin allergens with their non-allergic or weakly allergic homologs indicated that resistance to gastric digestion was not a strong predictor of sensitization potential (112). Taken together, these contradictory findings suggest the presence of additional factors which may complement or, in some cases supersede the influence of protein stability in the sensitization process-some of which will be discussed in the following sections.

\section{LIPID LIGANDS AS MODULATORS OF ABUNDANCE AND STABILITY}

Previous studies have shown that many allergen families are capable of binding lipids and other hydrophobic ligands (113). This activity could allow allergens to perturb biological barriers or deliver immunomodulatory ligands such as bacterial lipids or pollen-associated lipid mediators directly to the immune system, facilitating sensitization (114-118). However, the presence of lipid ligands or adjuvants could influence both abundance and stability, further contributing to allergenicity. For example, lipid emulsion significantly enhanced the resistance of allergenic fish parvalbumins to gastric digestion, facilitating exposure of the intact antigen to the immune system (119). Similarly, mustard (Sin a 2) and peanut (Ara h 1) allergens have been shown to interact on the surface of phospholipid vesicles derived from their respective allergen source, protecting them from gastric digestion and increasing the apparent abundance of intact antigen upon encountering intestinal immune cells (120). This interaction also impaired antigen uptake and endosomal degradation of both Ara h 1 and Sin a 2, altering the kinetics of MHCII presentation and ultimately skewing the immune system toward a Th2 response in a manner similar to the stabilized Bet v 1 mutants (120).

Some allergens are also capable of binding specific hydrophobic ligands within a defined cavity or pocket, opening up additional avenues through which endosomal degradation could be altered. This is exemplified by the cockroach allergen Bla g 1. The structure of Bla g 1 encloses an exceptionally large hydrophobic cavity that can accommodate up to 4 phospholipid or 8 fatty-acids, with a mixture of saturated and unsaturated fatty acids representing its natural ligands when purified from its natural allergen source $(121,122)$. While the unloaded form of Bla g 1 is relatively unstable, binding of its natural fatty-acid ligands or other hydrophobic cargoes into its hydrophobic cavity significantly enhanced conformational stability. This enhancement was strongly dependent on ligand acyl-chain length with 18 carbon (C18) fatty acids yielding maximal stability, and correlated with a decrease in T-cell epitope 


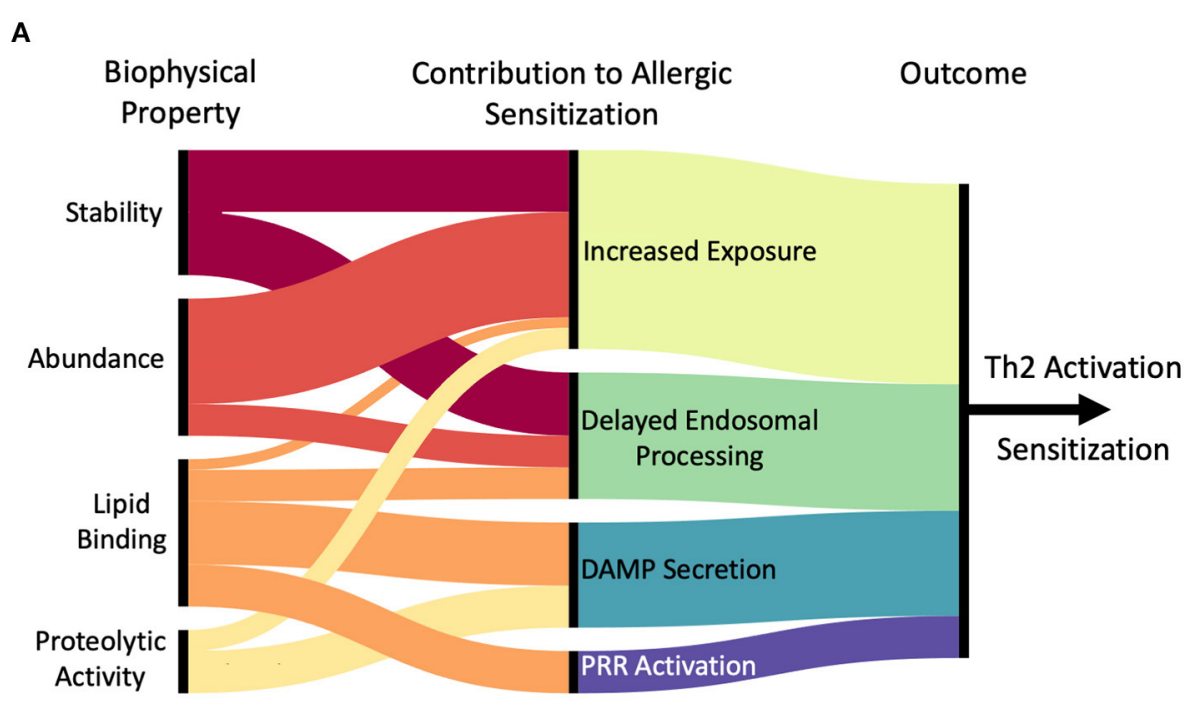

B

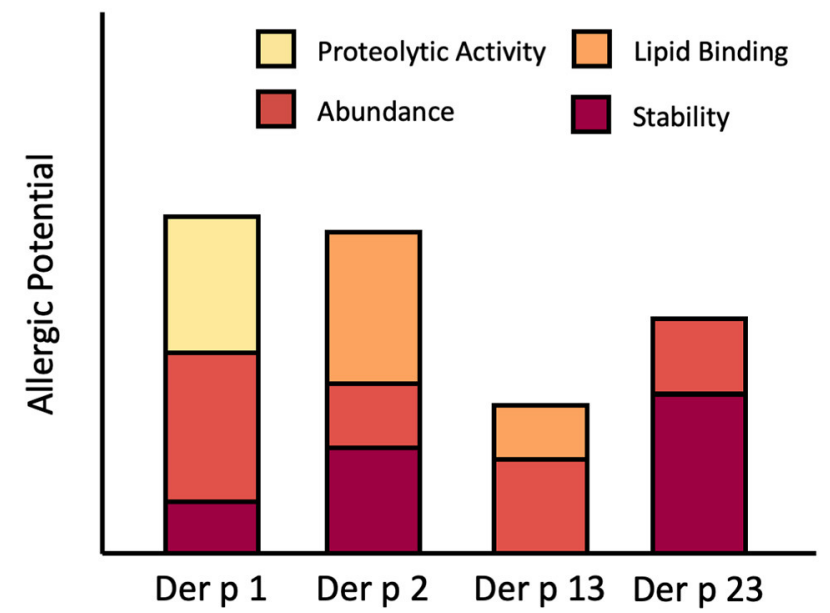

FIGURE 4 | Role of stability, abundance, and biological activity in allergic sensitization. (A) Artistic rendition summarizing potential pathways through which stability, abundance, and biological activity can promote allergic sensitization by facilitating exposure to the immune system, altering the kinetics of endosomal processing, triggering the release of danger-associated molecular patterns (DAMP) such as IL-33 and IL-8, or direct stimulation of Pattern-Recognition Receptors (PRR) such as TLR2. Connecting lines depict likely connections. For example, stability may contribute to both increased exposure and delayed endosomal processing. On the other hand, we have found little evidence that proteolytic activity contributes to delayed endosomal processing, hence there is not a connection drawn. Note that the relative contribution of these individual factors can differ between specific allergens, as shown for several example mite allergens in (B). Der $\mathrm{p} 1$ is a major allergen from mites primarily because of proteolytic activity and high abundance while Der $\mathrm{p} 2$ is an abundant lipid-binding allergen. In contrast, Der $\mathrm{p} 13$ is a minor allergen with low stability and moderate abundance and lipid binding capability, while Der $\mathrm{p} 23$ has average abundance, but exceptional stability. Figure generated using RAWGraphs (149).

generation when subjected to Cathepsin proteolysis, providing a direct link between the fold stability and endosomal persistence [Figure 3; (122)]. While Bla g 1 is notable for its large lipid binding capacity ( $>10 \% \mathrm{w} / \mathrm{w}$ under full stoichiometric binding), similar effects have been observed in less extreme systems. This is best exemplified by the birch allergen Bet $\mathrm{v} 1$, whose structure includes a hydrophobic cavity that can accommodate a variety of ligands, albeit at a much lower stoichiometry of 1-2 (123-125). As with Bla g 1, loading Bet v 1 with phytoprostanes and brassinosteroids from its natural allergen source significantly enhanced fold stability, inhibiting antigen processing and T-cell stimulation (123). Interestingly, one of these Bet $\mathrm{v} 1$ ligands $\left(\mathrm{PPE}_{1}\right)$ was also found to covalently inhibit Cathepsin S, providing an additional mechanism through which hydrophobic ligands can influence the stability, processing, and immunogenicity of allergic proteins (123). 
While the $\Delta G$ of ligand binding generally enhances the thermodynamic stability of the resulting complex (126), key exceptions exist. One illustrative example can be found among plant Lipid Transfer Proteins (LTP). While binding of their namesake ligands enhanced the thermostability and proteolytic resistance of LTP's from lentils and grapes $(127,128)$, the reverse effect was observed for their counterparts from wheat (129). The increased susceptibility of the latter was attributed to the displacement of aromatic residues from the hydrophobic core upon ligand binding, resulting in the increased exposure of chymotryptic cut sites and highlighting the need to consider the effects of ligand binding on a case-by-case basis, even when comparing potential allergens within the same protein family.

\section{ADDITIONAL CONSIDERATIONS: BIOLOGICAL ACTIVITY}

Based on the aforementioned studies, we developed a robust model through which the biophysical properties of allergens act to enhance sensitization by increasing the likelihood of exposure and altering the rate of endosomal processing and antigen presentation. This framework also allows us to account for the seemingly anomalous behavior of allergens such as Bet $\mathrm{v} 1$, Bla $g$ 1, and Phl p 4 (29). Even with this mechanistic understanding there are still several proteins which do not follow this trend, highlighting alternative pathways through which antigens can stimulate an allergic response through their biological activities rather than innate biophysical properties. For instance, the mite protein Der p 13 is markedly less stable than its nonallergic counterparts, severely compromising its ability to resist endosomal degradation (28). However, it is still able to induce a Th2 response (130). Biophysical studies identify Der p 13 as a fatty-acid binding protein (FABP) (130). In this capacity it is able to stimulate the membrane-bound pattern-recognition receptor (PRR) TLR2 via the delivery of fatty acid ligands, stimulating production of the pro-inflammatory cytokine IL8 (130). Der p 13 sensitization was also dependent on Serum Amyloid A (SAA), a soluble lipoprotein which at the time had no known immunological function (131). Subsequent studies identified SAA as a novel, soluble PRR which stimulates the release of IL-33 upon binding of FABP ligands, providing an additional mechanism through which Der p 13 can promote allergic sensitization independent of endosomal degradation and MHCII presentation (131). IL-33 is a pro-inflammatory Danger Associated Molecular Pattern (DAMP) or alarmin that is usually released in response to cellular damage (132). Other lipidbinding allergens such as Bla $\mathrm{g} 1$ and Bet $\mathrm{v} 1$ could ellicit a similar effect through destabilizing the plasma membrane of epithelial cells. In the case of the former, this is mediated by the delivery of unsaturated fatty acids into biological membranes while the latter is able to insert into a lipid bilayer, presumably disrupting lipid organization and packing $(114,133)$. In this capacity, the lipid-binding abilities of Bet $\mathrm{v} 1$ and Bla $\mathrm{g} 1$ play a dual role in stabilizing their respective ligands while simultaneously contributing to their pro-inflammatory biological functions. These examples highlight the multifaceted nature of

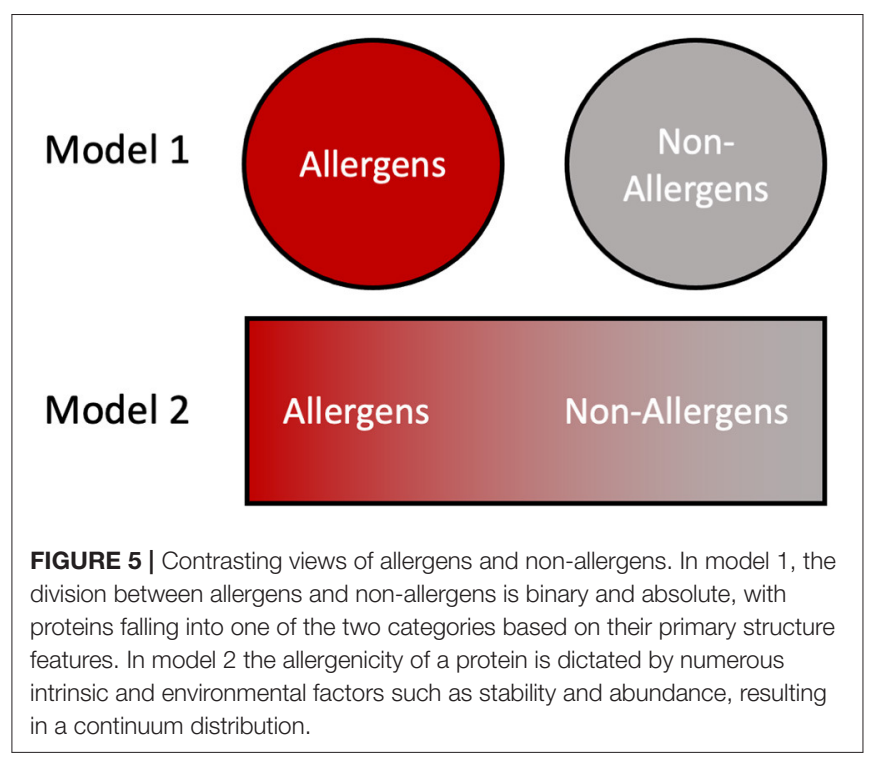

allergic sensitization, along with the need to consider not only the biophysical properties of allergenic proteins, but also their interactions with other environmental co-adjuvants or the host's own biological systems. A survey of over 700 allergens indicated that a significant portion $(>7 \%)$ could be classified as lipidbinding proteins, with some reviews claiming that half of the major allergens share this trait $(5,134)$. This suggests that the mechanisms outlined above are generally applicable across a wide range of antigenic proteins.

The Radauer study also found that hydrolases, particularly proteases, were equally over-represented among allergenic proteins suggesting that this functionality might also contribute to the sensitization process $(5,135)$. One mechanism through which this could occur is via the cleavage of proteinaseactivated receptor 2 (PAR2), activation of which results in the release of pro-inflammatory cytokines such as IL-8 and IL33. Indeed, both purified allergens and whole allergen extracts from cockroaches, dust mites and mold were able to stimulate a PAR2 in a proteolytic activity-dependent manner, resulting in a pro-inflammatory response (136-139). It should be noted that proteolytic cleavage of the IL-33 precursor is required to generate the mature, immunologically active cytokine (140). This reaction is normally carried out by inflammatory proteases from activated immune cells. However, this process could be mimicked by an alarming range of environmental and food allergens including both serine (Der p 3, Der p 6) and cysteine (Der p 1) proteases from house dust mites (141-143). Finally, the proteolytic activity of allergens such as Der $\mathrm{p} 1$, Per a 10 (cockroach), and Act d 1 (kiwifruit) can allow them to enhance epithelial barrier permeability through the direct proteolysis of tight junctions and other extracellular structures, facilitating exposure while further triggering alarmin production (144-148). In the case of Der $\mathrm{p} 1$, this proteolytic activity has been shown to enhance the allergenicity of an albumin "bystander" antigen, raising the interesting possibility that biologically-active allergens could act as adjuvants for other components of the exposome. 
These examples provide ample evidence that biological activity can complement the lackluster stability and/or abundance of allergic proteins such as Der p 1 or Bet $\mathrm{v} 1$ to yield a proinflammatory immune response, while the diverse mechanisms through which this enhancement occurs further highlights the multifaceted nature of allergic sensitization.

\section{CONCLUDING STATEMENTS}

It is well-established that both abundance and stability contribute to the sensitization process. However, their role is not always as straightforward as one would intuitively expect. While exposure is no doubt a pre-requisite for sensitization, the timing and duration of exposure, rather than its absolute intensity, appear to be the major determinants of allergenicity. Turning to stability, we see a similar relationship, with the kinetics of endosomal processing and MHCII loading representing key steps in the sensitization process. These findings suggest that the correlation between abundance, stability, and allergenicity is not a linear relationship as has been previously thought $(18,19,92)$. Instead, there are defined ranges for both parameters within which a protein is most likely to become allergenic. The innate biological activity of many allergens can potentially influence both of these factors, while simultaneously promoting allergic sensitization through other mechanisms such as the release of DAMPS or direct stimulation of PRR's, highlighting the multifaceted nature of allergic sensitization (Figure 4).

The non-linear relationship between stability and allergenicity (Figure 2) raises the possibility for novel immunotherapeutic strategies centered around hypoallergenic variants of naturally occurring allergens with altered stability. For example, stabilized $\mathrm{N}$-terminal truncations of the mite allergen Blo t 5 have been shown to enhance IL-10 production and suppress IL-4, skewing the immune system toward a modified Th2 response (98). Building upon this approach, a hybrid Blo t 5/Blo t 21 molecule has been developed as a potential allergy therapeutic (150). Here, the authors were able to retain the same endosomal degradation patterns while reducing IgE binding to the intact protein (98, 150). The enhanced stability of the hybrid molecule ensured that these resulting endosomal fragments yielded a protective response against their wild-type counterparts. Antigenic Bet $\mathrm{v} 1$ peptide fragments and stabilized Bet $\mathrm{v} 1$ trimers have also been shown to be safe and effective immunotherapeutic candidates (151-153). The latter has been shown to form large aggregates, potentially hindering antigen processing while the former mimics the epitope generation kinetics of a destabilized Bet $\mathrm{v} 1$ variant, suggesting that immunotherapeutic strategies can exploit the bimodal model shown in Figure 2 in both directions. In more extreme examples, whole allergens or antigenic fragments have been conjugated onto stable protein scaffolds. The resulting fusion proteins were able to stimulate the release of tolerogenic cytokines such as IL-10 and IFN$\gamma$, stimulating the production of blocking antibodies (154, 155). Due to the bimodal relationship between stability and allergenicity, the effect of stabilizing/destabilizing mutations is heavily dependent on the biophysical properties of the initial wild-type allergen. This is embodied by the protective effects observed in both stabilized and destabilized Bet $\mathrm{v} 1$ variants described in Figure 2 (88, 156), underscoring the need to carefully consider the nuanced role of stability in allergic sensitization when designing immunotherapeutic candidates.

In addition to enhancing protein stability, hydrophobic ligands are able to directly promote sensitization through a variety of pathways, as summarized in Figure 4. While this additional activity further complicates efforts to develop hypoallergenic variants of Bet $\mathrm{v} 1$ and other lipid-binding allergens, it also opens up additional avenues of development. For instance, Bet v 1 without ligands is deficient in Th2 stimulation, providing a convenient avenue for the development of immunotherapeutic compounds (157). Similarly, the sensitization potential of Ber e 1 and Pru p 3 were also highly dependent on the presence of lipid ligands $(158,159)$. Given the prevalence of lipid binding among allergens (5), removal and/or replacement of endogenous ligands could provide a simple and convenient approach to generate hypoallergenic compounds for immunotherapeutic applications.

Finally, for this topical edition of Frontiers in Allergy, "What makes an Allergen, an Allergen?", we present two different models regarding the relationship between allergens and their non-allergen counterparts, which are applicable in different circumstances [Figure 5; (160)]. For example, a clinical allergologist typically thinks of discrete allergens and their use in diagnosing the sensitizing organism, for prescribing appropriate avoidance, and possible therapeutic treatments (161). Similarly, cross-reactivity risks can be assessed using bioinformatics tools and immunological assays against known allergen sequences; clearly these are valuable medical models. However, these strategies assume a binary approach with proteins being classified as either allergens or non-allergens (Figure 5, model 1). When addressing the question, "What makes an allergen, an allergen?", the data in this paper favors a more probabilistic interpretation in which multiple factors including stability and abundance contribute to allergic sensitization (160). This gives rise to a continuum model (Figure 5, model 2) where, many proteins can become allergens or vice versa depending on the context of presentation and the individual biophysical properties.

\section{AUTHOR CONTRIBUTIONS}

AF and GM wrote the paper. Both authors contributed to the article and approved the submitted version.

\section{FUNDING}

This review was supported by the Intramural Research Program of the NIH, National Institute of Environmental Health Sciences, Z01-ES102906 (GM).

\section{ACKNOWLEDGMENTS}

The authors wish to thank Drs. Don Cook and Paivi Salo for a critical reading of the manuscript. 


\section{REFERENCES}

1. Dierick BJH, van der Molen T, Flokstra-de Blok BMJ, Muraro A, Postma MJ, Kocks JWH, et al. Burden and socioeconomics of asthma, allergic rhinitis, atopic dermatitis and food allergy. Expert Rev Pharmacoeconomics Outcomes Res. (2020) 20:437-53. doi: 10.1080/14737167.2020.1819793

2. Fischer D, Vander Leek TK, Ellis AK, Kim H. Anaphylaxis. Allergy, Asthma Clin Immunol. (2018) 14(Suppl. 2):54. doi: 10.1186/s13223-018-0283-4

3. Aung T, Bisognano JD, Morgan MA. Allergic respiratory disease as a potential co-morbidity for hypertension. Cardiol J. (2010) 17:443-7.

4. Wood RA, Camargo CA, Lieberman P, Sampson HA, Schwartz LB, Zitt $\mathrm{M}$, et al. Anaphylaxis in America: the prevalence and characteristics of anaphylaxis in the United States. J Allergy Clin Immunol. (2014) 133:461-7. doi: 10.1016/j.jaci.2013.08.016

5. Radauer C, Bublin M, Wagner S, Mari A, Breiteneder H. Allergens are distributed into few protein families and possess a restricted number of biochemical functions. J Allergy Clin Immunol. (2008) 121:847-52. doi: 10.1016/j.jaci.2008.01.025

6. Custovic A. To what extent is allergen exposure a risk factor for the development of allergic disease? Clin Exp Allergy. (2015) 45:54-62. doi: 10.1111/cea.12450

7. Foong RX, Brough $\mathrm{H}$. The role of environmental exposure to peanut in the development of clinical allergy to peanut. Clin Exp Allergy. (2017) 47:1232-8. doi: $10.1111 /$ cea. 12992

8. Constant S, Pfeiffer C, Woodard A, Pasqualini T, Bottomly K, Constant $\mathrm{BS}$, et al. Extent of $\mathrm{T}$ cell receptor ligation can determine the functional differentiation of naive CD4+ T cells. J Exp Med. (1995) 182:1591-6. doi: 10.1084/jem.182.5.1591

9. Tao X, Constant S, Jorritsma P, Bottomly K. Strength of TCR signal determines the costimulatory requirements for Th1 and Th2 CD4+ T cell differentiation. J Immunol. (1997) 159:5956-63.

10. Egger M, Jurets A, Wallner M, Briza P, Ruzek S, Hainzl S, et al. Assessing protein immunogenicity with a dendritic cell line-derived endolysosomal degradome. PLoS ONE. (2011) 6:e17278. doi: 10.1371/journal.pone.0017278

11. Winter P, Stubenvoll S, Scheiblhofer S, Joubert IA, Strasser L, Briganser C, et al. In silico design of $\mathrm{Phl} \mathrm{p} 6$ variants with altered fold-stability significantly impacts antigen processing, immunogenicity and immune polarization. Front Immunol. (2020) 11:1824. doi: 10.3389/fimmu.2020.01824

12. Lehrer SB, Ibanez MD, McCants ML, Daul CB, Morgan JE. Characterization of water-soluble shrimp allergens released during boiling. J Allergy Clin Immunol. (1990) 85:1005-13. doi: 10.1016/0091-6749(90)90044-5

13. Daul CB, Slattery M, Reese G, Lehrer SB. Identification of the major brown shrimp (Penaeus aztecus) allergen as the muscle protein tropomyosin. Int Arch Allergy Immunol. (1994) 105:49-55. doi: 10.1159/000236802

14. Walczyk NE, Smith PMC, Tovey E, Wright GC, Fleischfresser DB, Roberts TH. Analysis of crude protein and allergen abundance in peanuts (Arachis hypogaea cv. Walter) from three growing regions in Australia. J Agric Food Chem. (2013) 61:3714-25. doi: 10.1021/jf305347r

15. Gore JC, Schal C. Expression, production and excretion of Bla g 1, a major human allergen, in relation to food intake in the German cockroach, Blattella germanica. Med Vetinary Entomol. (2005) 19:127-34. doi: 10.1111/j.0269-283X.2005.00550.x

16. Visez $N$, de Nadaï $P$, Choël $M$, Farah J, Hamzé $M$, Sénéchal $H$, et al. Biochemical composition of Phleum pratense pollen grains: a review. Mol Immunol. (2021) 136:98-109. doi: 10.1016/j.molimm.2021.05.014

17. Batard T, Hrabina A, Xue ZB, Chabre H, Lemoine P, Couret MN, et al. Production and proteomic characterization of pharmaceutical-grade Dermatophagoides pteronyssinus and Dermatophagoides farinae extracts for allergy vaccines. Int Arch Allergy Immunol. (2006) 140:295-305. doi: $10.1159 / 000093707$

18. Sarpong SB, Hamilton RG, Eggleston PA, Adkinson NF. Socioeconomic status and race as risk factors for cockroach allergen exposure and sensitization in children with asthma. J Allergy Clin Immunol. (1996) 97:1393-401. doi: 10.1016/S0091-6749(96)70209-9

19. Eggleston PA, Rosenstreich D, Lynn H, Gergen P, Baker D, Kattan M, et al. Relationship of indoor allergen exposure to skin test sensitivity in inner-city children with asthma. J Allergy Clin Immunol. (1998) 102:563-70. doi: 10.1016/S0091-6749(98)70272-6
20. Huss K, Adkinson NF, Eggleston PA, Dawson C, Van Natta ML, Hamilton RG. House dust mite and cockroach exposure are strong risk factors for positive allergy skin test responses in the Childhood Asthma Management Program. J Allergy Clin Immunol. (2001) 107:48-54. doi: $10.1067 /$ mai.2001.111146

21. Olmedo O, Goldstein IF, Acosta L, Divjan A, Rundle AG, Chew GL, et al. Neighborhood differences in exposure and sensitization to cockroach, mouse, dust mite, cat, and dog allergens in New York City. J Allergy Clin Immunol. (2011) 128:284-92.e7. doi: 10.1016/j.jaci.2011.02.044

22. Carlsten C, Dimich-Ward H, Becker AB, Ferguson A, Chan HW, Dybuncio $\mathrm{A}$, et al. Indoor allergen exposure, sensitization, and development of asthma in a high-risk birth cohort. Pediatr Allergy Immunol. (2010) 21(4 Pt 2):e7406. doi: 10.1111/j.1399-3038.2010.01021.x

23. Tovey ER, Willenborg CM, Crisafulli DA, Rimmer J, Marks GB. Most personal exposure to house dust mite aeroallergen occurs during the day. PLoS ONE. (2013) 8:e69900. doi: 10.1371/journal.pone.0069900

24. Tovey ER, Liu-Brennan D, Garden FL, Oliver BG, Perzanowski MS, Marks GB. Time-based measurement of personal mite allergen bioaerosol exposure over 24 hour periods. PLoS ONE. (2016) 11:e0153414. doi: 10.1371/journal.pone.0153414

25. Niesler A, Scigała G, Łudzeń-Izbińska B. Cat (Fel d 1) and dog (Can f 1) allergen levels in cars, dwellings and schools. Aerobiologia. (2016) 32:571-80. doi: 10.1007/s10453-016-9433-7

26. Sander I, Lotz A, Neumann HD, Czibor C, Flagge A, Zahradnik E, et al. Indoor allergen levels in settled airborne dust are higher in day-care centers than at home. Allergy Eur J Allergy Clin Immunol. (2018) 73:1263-75. doi: $10.1111 /$ all.13371

27. Dharmage SC, Lodge CL, Matheson MC, Campbell B, Lowe AJ. Exposure to cats: update on risks for sensitization and allergic diseases. Curr Allergy Asthma Rep. (2012) 12:413-23. doi: 10.1007/s11882-012-0288-x

28. Ogburn RN, Randall TA, Xu Y, Roberts JH, Mebrahtu B, Karnuta JM, et al. Are dust mite allergens more abundant and/or more stable than other Dermatophagoides pteronyssinus proteins? J Allergy Clin Immunol. (2017) 139:1030-2.e1. doi: 10.1016/j.jaci.2016.08.016

29. Cabrera A, Randall TA, Ogburn RN, Mebrahtu B, Johnson JHR, Foo ACY, et al. Are allergens more abundant and/or more stable than other proteins in pollens and dust? Allergy Eur J Allergy Clin Immunol. (2019) 75:1267-9. doi: $10.1111 /$ all.14121

30. Fu T-J, Abbott UR, Hatzos C. digestibility of food allergens and nonallergenic proteins in simulated gastric fluid and simulated intestinal fluid - a comparative study. J Agric Food Chem. (2002) 50:7154-60. doi: 10.1021/jf020599h

31. Astwood JD, Leach JN, Fuchs RL. Stability of food allergens to digestion in vitro. Nat Biotechnol. (1996) 14:1269-73. doi: 10.1038/nbt1096-1269

32. Herman RA, Woolhiser MM, Ladics GS, Korjagin VA, Schafer BB, Storer NP, et al. Stability of a set of allergens and non-allergens in simulated gastric fluid. Int J Food Sci Nutr. (2007) 58:125-41. doi: 10.1080/09637480601149640

33. Prodic I, Stanic-Vucinic D, Apostolovic D, Mihailovic J, Radibratovic M, Radosavljevic J, et al. Influence of peanut matrix on stability of allergens in gastric-simulated digesta: $2 S$ albumins are main contributors to the $\operatorname{IgE}$ reactivity of short digestion-resistant peptides. Clin Exp Allergy. (2018) 48:731-40. doi: $10.1111 /$ cea.13113

34. Bernard H, Ah-Leung S, Drumare MF, Feraudet-Tarisse C, Verhasselt V, Wal JM, et al. Peanut allergens are rapidly transferred in human breast milk and can prevent sensitization in mice. Allergy Eur J Allergy Clin Immunol. (2014) 69:888-97. doi: 10.1111/all.12411

35. Schocker F, Baumert J, Kull S, Petersen A, Becker WM, Jappe U. Prospective investigation on the transfer of Ara h 2, the most potent peanut allergen, in human breast milk. Pediatr Allergy Immunol. (2016) 27:348-55. doi: $10.1111 /$ pai.12533

36. Moreno FJ, Mellon FA, Wickham MSJ, Bottrill AR, Mills ENC. Stability of the major allergen Brazil nut $2 S$ albumin (Ber e 1) to physiologically relevant in vitro gastrointestinal digestion. FEBS J. (2005) 272:341-52. doi: $10.1111 / \mathrm{j} .1742-4658.2004 .04472 . \mathrm{x}$

37. Aalberse RC, Mueller GA, Derksen NIL, Aalberse JA, Edwards LL, Pomés A, et al. Identification of the amino-terminal fragment of Ara h 1 as a major target of the IgE-binding activity in the basic peanut protein fraction. Clin Exp Allergy. (2020) 50:401-5. doi: 10.1111/cea.13554 
38. Downs ML, Semic-Jusufagic A, Simpson A, Bartra J, Fernandez-Rivas M, Rigby NM, et al. Characterization of low molecular weight allergens from English walnut (Juglans regia). J Agric Food Chem. (2014) 62:11767-75. doi: 10.1021/jf504672m

39. Peng RD, Paigen B, Eggleston PA, Hagberg KA, Krevans M, Curtin-Brosnan $\mathrm{J}$, et al. Both the variability and level of mouse allergen exposure influence the phenotype of the immune response in workers at a mouse facility. J Allergy Clin Immunol. (2011) 128:390-6.e7. doi: 10.1016/j.jaci.2011.04.050

40. Torjusen EN, Diette GB, Breysse PN, Curtin-Brosnan J, Aloe C, Matsui EC. Dose-response relationships between mouse allergen exposure and asthma morbidity among urban children and adolescents. Indoor Air. (2013) 23:26874. doi: 10.1111/ina.12009

41. Simoneti CS, Freitas AS, Barbosa MCR, Ferraz E, de Menezes MB, Bagatin E, et al. Study of risk factors for atopic sensitization, asthma, and bronchial hyperresponsiveness in animal laboratory workers. J Occup Health. (2016) 58:7-15. doi: 10.1539/joh.15-0045-OA

42. Eich-Wanger C, Müller UR. Bee sting allergy in beekeepers. Clin Exp Allergy. (1998) 28:1292-8. doi: 10.1046/j.1365-2222.1998.00411.x

43. Müller UR. Bee venom allergy in beekeepers and their family members. Curr Opin Allergy Clin Immunol. (2005) 5:343-7. doi: 10.1097/01.all.0000173783.42906.95

44. Bousquet J, Ménardo JL, Aznar R, Robinet-Lévy M, Michel FB. Clinical and immunologic survey in beekeepers in relation to their sensitization. J Allergy Clin Immunol. (1984) 73:332-40. doi: 10.1016/0091-6749(84)90405-6

45. Kalogeromitros D, Makris M, Gregoriou S, Papaioannou D, Katoulis A, Stavrianeas NG. Pattern of sensitization to honeybee venom in beekeepers: a 5-year prospective study. Allergy Asthma Proc. (2006) 27:3837. doi: 10.2500/aap.2006.27.2901

46. James LK, Till SJ. Potential mechanisms for IgG4 inhibition of immediate hypersensitivity reactions. Curr Allergy Asthma Rep. (2016) 16:1-7. doi: 10.1007/s11882-016-0600-2

47. Chliva C, Aggelides X, Makris M, Katoulis A, Rigopoulos D, Tiligada E. Comparable profiles of serum histamine and IgG4 levels in allergic beekeepers. Allergy Eur J Allergy Clin Immunol. (2015) 70:457-60. doi: 10.1111/all.12568

48. Meiler F, Zumkehr J, Klunker S, Rückert B, Akdis CA, Akdis M. In vivo switch to IL-10-secreting T regulatory cells in high dose allergen exposure. J Exp Med. (2008) 205:2887-98. doi: 10.1084/jem.20080193

49. Coomes SM, Kannan Y, Pelly VS, Entwistle LJ, Guidi R, Perez-Lloret J, et al. CD4 + Th2 cells are directly regulated by IL-10 during allergic airway inflammation. Mucosal Immunol. (2017) 10:150-61. doi: 10.1038/mi.2016.47

50. Couper KN, Blount DG, Riley EM. IL-10: the master regulator of immunity to infection. J Immunol. (2008) 180:5771-7. doi: 10.4049/jimmunol.180.9.5771

51. Lin AA, Freeman AF, Nutman TB. IL-10 indirectly downregulates IL-4induced IgE production by human B cells. ImmunoHorizons. (2018) 2:398406. doi: 10.4049/immunohorizons. 1800076

52. Jones M, Jeal H, Schofield S, Harris JM, Shamji MH, Francis JN, et al. Ratspecific IgG and IgG4 antibodies associated with inhibition of IgE-allergen complex binding in laboratory animal workers. Occup Environ Med. (2014) 71:619-23. doi: 10.1136/oemed-2014-102119

53. Krop EJM, Doekes G, Heederik DJJ, Aalberse RC, Van Der Zee JS. IgG4 antibodies against rodents in laboratory animal workers do not protect against allergic sensitization. Allergy Eur J Allergy Clin Immunol. (2011) 66:517-22. doi: 10.1111/j.1398-9995.2010.02508.x

54. Jeal H, Draper A, Harris J, Taylor AN, Cullinan P, Jones $M$. Modified Th2 responses at high-dose exposures to allergen: using an occupational model. Am J Respir Crit Care Med. (2006) 174:21-5. doi: 10.1164/rccm.200506-964OC

55. Grilo JR, Kitzmüller C, Aglas L, Sánchez Acosta G, Vollmann U, Ebner $\mathrm{C}$, et al. IgE-cross-blocking antibodies to Fagales following sublingual immunotherapy with recombinant Bet v 1. Allergy Eur J Allergy Clin Immunol. (2021) 76:2555-64. doi: 10.1111/all.14817

56. Jutel M, Pichler WJ, Skrbic D, Urwyler A, Dahinden C, Muller UR. Bee venom immunotherapy results in decrease of IL-4 and IL-5 and increase of IFN- $\gamma$ secretion in specific allergen-stimulated T cell cultures. J Immunol. (1995) 154:4187-94.
57. Sampath V, Nadeau KC. Newly identified T cell subsets in mechanistic studies of food immunotherapy. J Clin Invest. (2019) 129:1431-40. doi: 10.1172/JCI124605

58. Sánchez Acosta G, Kinaciyan T, Kitzmüller C, Möbs C, Pfützner W, Bohle B. IgE-blocking antibodies following SLIT with recombinant Mal d 1 accord with improved apple allergy. J Allergy Clin Immunol. (2020) 146:894-900.e2. doi: 10.1016/j.jaci.2020.03.015

59. Jeannin P, Lecoanet S, Delneste Y, Gauchat JF, Bonnefoy JY. IgE versus IgG4 production can be differentially regulated by IL-10. J Immunol. (1998) 160:3555-61.

60. Akbari O, DeKruyff RH, Umetsu DT. Pulmonary dendritic cells producing IL-10 mediate tolerance induced by respiratory exposure to antigen. Nat Immunol. (2001) 2:725-31. doi: 10.1038/90667

61. Woodcock A, Lowe LA, Murray CS, Simpson BM, Pipis SD, Kissen P, et al. Early life environmental control: effect on symptoms, sensitization, and lung function at age 3 years. Am J Respir Crit Care Med. (2004) 170:433-9. doi: 10.1164/rccm.200401-083OC

62. Woodcock H, Craven M, Hassall R, Hadley E, Simpson A, Custovic A. Dust mite allergens are not carried only on large particles. Thorax. (1999) 10:258-60. doi: 10.1034/j.1399-3038.1999.00050.x

63. van Boven FE, de Jong NW, Loomans MGLC, Braunstahl GJ, Gerth van Wijk $\mathrm{R}$, Arends LR. Describing fluctuating indoor aerosol dust measurements with application to house dust mite allergens. Sci Rep. (2020) 10:16897. doi: 10.1038/s41598-020-73839-x

64. de Blay F, Heymann PW, Chapman MD, Platts-Mills TAE. Airborne dust mite allergens: comparison of group II allergens with group I mite allergen and cat-allergen Fel d I. J Allergy Clin Immunol. (1991) 88:919-26. doi: 10.1016/0091-6749(91)90249-N

65. Wu T, Holopainen R, Viitanen A, Vainiotalo S, Tuomi T, Keskinen J, et al. Infant and adult inhalation exposure to resuspended biological particulate matter. Environ Sci Technol. (2018) 52: 237-47. doi: 10.1021/acs.est.7b04183

66. Gomes C, Freihaut J, Bahnfleth W. Resuspension of allergencontaining particles under mechanical and aerodynamic disturbances from human walking. Atmos Environ. (2007) 41:5257-70. doi: 10.1016/j.atmosenv.2006.07.061

67. Custovic A, Smith A, Green R, Woodcock A. Distribution and aerodynamic characteristics of major cat allergen Fel d 1. Thorax. (1996) 53:33-8. doi: $10.1136 /$ thx.53.1.33

68. Custovic A, Green R, Fletcher A, Smith A, Pickering CAC, Chapman MD, et al. Aerodynamic properties of the major dog allergen Can $\mathrm{f} 1$ : distribution in homes, concentration, and particle size of allergen in the air. Am J Respir Crit Care Med. (1997) 155:94-8. doi: 10.1164/ajrccm.155.1.9001295

69. Esty B, Permaul P, DeLoreto K, Baxi SN, Phipatanakul W. Asthma and allergies in the school environment. Clin Rev Allergy Immunol. (2019) 57:415-26. doi: 10.1007/s12016-019-08735-y

70. Platts-Mills TAE, Vaughan JW, Blumenthal K, Pollart Squillace S, Sporik RB. Serum IgG and IgG4 antibodies to Fel $\mathrm{d} 1$ among children exposed to $20 \mu \mathrm{g}$ Fel d 1 at home: Relevance of a nonallergic modified Th2 response. Int Arch Allergy Immunol. (2001) 124:126-9. doi: 10.1159/000053689

71. Tovey ER, Almqvist C, Li Q, Crisafulli D, Marks GB. Nonlinear relationship of mite allergen exposure to mite sensitization and asthma in a birth cohort. J Allergy Clin Immunol. (2008) 122:114-8, 118.e1-5. doi: 10.1016/j.jaci.2008.05.010

72. Platts-Mills T, Vaughan J, Squillace S, Woodfolk J, Sporik R. Sensitisation, asthma, and a modified Th2 response in children exposed to cat allergen: a population-based cross-sectional study. Lancet. (2001) 357:752-6. doi: 10.1016/S0140-6736(00)04168-4

73. Almqvist C, Egmar AC, Hedlin G, Lundqvist M, Nordvall SL, Pershagen $\mathrm{G}$, et al. Direct and indirect exposure to pets - risk of sensitization and asthma at 4 years in a birth cohort. Clin Exp Allergy. (2003) 33:1190-7. doi: 10.1046/j.1365-2222.2003.01764.x

74. Gupta RS, Springston EE, Smith B, Warrier MR, Pongracic J, Holl JL. Geographic variability of childhood food allergy in the United States. Clin Pediatr. (2012) 51:856-61. doi: 10.1177/0009922812448526

75. Elholm G, Linneberg A, Husemoen LLN, Omland, Grønager PM, Sigsgaard $\mathrm{T}$, et al. The Danish urban-rural gradient of allergic sensitization and disease in adults. Clin Exp Allergy. (2016) 46:103-11. doi: 10.1111/cea.12583 
76. Christensen SH, Timm S, Janson C, Benediktsdóttir B, Forsberg B, Holm $\mathrm{M}$, et al. A clear urban-rural gradient of allergic rhinitis in a populationbased study in Northern Europe. Eur Clin Respir J. (2016) 3:33463. doi: 10.3402/ecrj.v3.33463

77. Stemeseder T, Schweidler B, Doppler P, Klinglmayr E, Moser S, Lueftenegger $\mathrm{L}$, et al. Exposure to indoor allergens in different residential settings and its influence on IgE sensitization in a geographically confined Austrian cohort. PLoS ONE. (2017) 12:e0168686. doi: 10.1371/journal.pone.0168686

78. Riedler J, Braun-Fahrländer C, Eder W, Schreuer M, Waser M, Maisch $S$, et al. Exposure to farming in early life and development of asthma and allergy: a cross-sectional survey. Lancet. (2001) 358:1129-33. doi: 10.1016/S0140-6736(01)06252-3

79. Von Mutius E, Vercelli D. Farm living: effects on childhood asthma and allergy. Nat Rev Immunol. (2010) 10:861-8. doi: 10.1038/nri2871

80. Ober C, Sperling AI, von Mutius E, Vercelli D. Immune development and environment: lessons from Amish and Hutterite children. Curr Opin Immunol. (2017) 48:51-60. doi: 10.1016/j.coi.2017.08.003

81. Stein MM, Hrusch CL, Gozdz J, Igartua C, Pivniouk V, Murray SE, et al. Innate immunity and asthma risk in amish and hutterite farm children. $N$ Engl J Med. (2016) 375:411-21. doi: 10.1056/NEJMoa1508749

82. Langenkamp A, Messi M, Lanzavecchia A, Sallusto F. Kinetics of dendritic cell activation: impact on priming of TH1,TH2 and nonpolarized T cells. Nat Immunol. (2000) 1:311-6. doi: 10.1038/79758

83. Hosken NA, Shibuya K, Heath AW, Murphy KM, O'Garra A. The effect of antigen dose on CD4+ $\mathrm{T}$ helper cell phenotype development in a T cell receptor-ab-transgenic model. J Exp Med. (1995) 182:1579-84. doi: 10.1084 /jem.182.5.1579

84. Henrickson SE, Mempel TR, Mazo IB, Liu B, Artyomov MN, Zheng H, et al. $\mathrm{T}$ cell sensing of antigen dose governs interactive behavior with dendritic cells and sets a threshold for T cell activation. Nat Immunol. (2008) 9:282-91. doi: $10.1038 /$ ni1559

85. Ferreira F, Hirtenlehner K, Jilek A, Godnik-Cvar J, Breiteneder H, Grimm $\mathrm{R}$, et al. Dissection of immunoglobulin $\mathrm{E}$ and $\mathrm{T}$ lymphocyte reactivity of isoforms of the major birch pollen allergen Bet $\mathrm{v}$ 1: potential use of hypoallergenic isoforms for immunotherapy. J Exp Med. (1996) 183:599609. doi: 10.1084/jem.183.2.599

86. Grutsch S, Fuchs JE, Ahammer L, Kamenik AS, Liedl KR, Tollinger M. Conformational flexibility differentiates naturally occurring Bet $\mathrm{v} 1$ isoforms. Int J Mol Sci. (2017) 18:1-15. doi: 10.3390/ijms18061192

87. Freier R, Dall E, Brandstetter H. Protease recognition sites in Bet v la are cryptic, explaining its slow processing relevant to its allergenicity. Sci Rep. (2015) 5:12707. doi: 10.1038/srep12707

88. Wagner S, Radauer C, Bublin M, Hoffmann-Sommergruber K, Kopp T, Greisenegger EK, et al. Naturally occurring hypoallergenic Bet v 1 isoforms fail to induce IgE responses in individuals with birch pollen allergy. J Allergy Clin Immunol. (2008) 121:246-52. doi: 10.1016/j.jaci.2007.08.006

89. Ackaert C, Kofler S, Horejs-Hoeck J, Zulehner N, Asam C, Von Grafenstein $S$, et al. The impact of nitration on the structure and immunogenicity of the major birch pollen allergen Bet v 1.0101. PLoS ONE. (2014) 9:e104520. doi: 10.1371/journal.pone.0104520

90. Toda M, Reese G, Gadermaier G, Schulten V, Lauer I, Egger M, et al. Protein unfolding strongly modulates the allergenicity and immunogenicity of Pru $\mathrm{p}$ 3, the major peach allergen. J Allergy Clin Immunol. (2011) 128:1022-30.e17. doi: 10.1016/j.jaci.2011.04.020

91. Gadermaier G, Jahn-Schmid B, Vogel L, Egger M, Himly M, Briza P, et al. Targeting the cysteine-stabilized fold of Art v 1 for immunotherapy of Artemisia pollen allergy. Mol Immunol. (2010) 47:1292-8. doi: 10.1016/j.molimm.2009.11.029

92. Ohkuri T, Nagatomo S, Oda K, So T, Imoto T, Ueda T. A protein's conformational stability is an immunologically dominant factor: evidence that free-energy barriers for protein unfolding limit the immunogenicity of foreign proteins. J Immunol. (2010) 185:4199-205. doi: 10.4049/jimmunol.0902249

93. Razvi A, Scholtz JM. Lessons in stability from thermophilic proteins. Protein Sci. (2006) 15:1569-78. doi: 10.1110/ps.062130306

94. Ragone R. phenomenological similarities between protein denaturation and small-molecule dissolution: insights into the mechanism driving the thermal resistance of globular proteins. Proteins Struct Funct Genet. (2003) 64:792-4. doi: 10.1002/prot.10574

95. van Niel G, Wubbolts R, Stoorvogel W. Endosomal sorting of MHC class II determines antigen presentation by dendritic cells. Curr Opin Cell Biol. (2008) 20:437-44. doi: 10.1016/j.ceb.2008.05.011

96. Machado Y, Freier R, Scheiblhofer S, Thalhamer T, Mayr M, Briza P, et al. Fold stability during endolysosomal acidification is a key factor for allergenicity and immunogenicity of the major birch pollen allergen. J Allergy Clin Immunol. (2016) 137:1525-34. doi: 10.1016/j.jaci.2015.09.026

97. Wolf M, Aglas L, Twaroch TE, Steiner M, Huber S, Hauser M, et al. Endolysosomal protease susceptibility of Amb a 1 as a determinant of allergenicity. J Allergy Clin Immunol. (2018) 141:1488-91.e5. doi: 10.1016/j.jaci.2017.10.027

98. da Silva ES, Huber S, Alcantara-Neves NM, Asam C, Silveira EF, de Andrade Belitardo EMM, et al. N-terminal peptide deletion influences immunological and structural features of Blo t 5. Allergy Eur J Allergy Clin Immunol. (2020) 75:1503-7. doi: 10.1111/all.14176

99. So T, Ito HO, Hirata M, Ueda T, Imoto T. Contribution of conformational stability of hen lysozyme to induction of type 2 T-helper immune responses. Immunology. (2001) 104:259-68. doi: 10.1046/j.1365-2567.2001.01314.x

100. Nakamura H, Ohkuri T, So T, Ueda T. Relationship between the magnitude of IgE production in mice and conformational stability of the house dust mite allergen, Der p 2. Biochim Biophys Acta Gen Subj. (2016) 1860:2279-84. doi: 10.1016/j.bbagen.2016.04.014

101. Villadangos JA, Ploegh HL. Proteolysis in MHC class II antigen presentation: who's in charge? Immunity. (2000) 12:233-9. doi: 10.1016/S1074-7613(00)80176-4

102. Sadegh-Nasseri S, Kim AR. Selection of immunodominant epitopes during antigen processing is hierarchical. Mol Immunol. (2019) 113:115-9. doi: 10.1016/j.molimm.2018.08.011

103. Kim A, Hartman IZ, Poore B, Boronina T, Cole RN, Song N, et al. Divergent paths for the selection of immunodominant epitopes from distinct antigenic sources. Nat Commun. (2014) 5:5369. doi: 10.1038/ncomms6369

104. Kim AR, Sadegh-Nasseri S. Determinants of immunodominance for CD4 T cells. Curr Opin Immunol. (2015) 34:9-15. doi: 10.1016/j.coi.2014. 12.005

105. Toda M, Kasai M, Hosokawa H, Nakano N, Taniguchi Y, Inouye S, et al. DNA vaccine using invariant chain gene for delivery of CD4+T cell epitope peptide derived from Japanese cedar pollen allergen inhibits allergen-specific IgE response. Eur J Immunol. (2002) 32:1631-9.3.

106. Rosskopf S, Jutz S, Neunkirchner A, Candia MR, Jahn-Schmid B, Bohle $B$, et al. Creation of an engineered APC system to explore and optimize the presentation of immunodominant peptides of major allergens. Sci Rep. (2016) 6:31580. doi: 10.1038/srep31580

107. Senti G, Crameri R, Kuster D, Johansen P, Martinez-Gomez JM, Graf $\mathrm{N}$, et al. Intralymphatic immunotherapy for cat allergy induces tolerance after only 3 injections. J Allergy Clin Immunol. (2012) 129:1290-6. doi: 10.1016/j.jaci.2012.02.026

108. Yu S, Han B, Liu S, Wang H, Zhuang W, Huang Y, et al. Derp1modified dendritic cells attenuate allergic inflammation by regulating the development of $\mathrm{T}$ helper type1(Th1)/Th2 cells and regulatory $\mathrm{T}$ cells in a murine model of allergic rhinitis. Mol Immunol. (2017) 90:172-81. doi: 10.1016/j.molimm.2017.07.015

109. Custovic A, Simpson BM, Simpson A, Hallam CL, Marolia H, Walsh D, et al. Current mite, cat, and dog allergen exposure, pet ownership, and sensitization to inhalant allergens in adults. J Allergy Clin Immunol. (2003) 111:402-7. doi: 10.1067/mai.2003.55

110. Kamath SD, Scheiblhofer S, Johnson CM, Machado Y, McLean T, Taki $\mathrm{AC}$, et al. Effect of structural stability on endolysosomal degradation and T-cell reactivity of major shrimp allergen tropomyosin. Allergy Eur J Allergy Clin Immunol. (2020) 75:2909-19. doi: 10.1111/all. 14410

111. Foster ES, Kimber I, Dearman RJ. Relationship between protein digestibility and allergenicity: comparisons of pepsin and cathepsin. Toxicology. (2013) 309:30-8. doi: 10.1016/j.tox.2013.04.011

112. Akkerdaas J, Totis M, Barnett B, Bell E, Davis T, Edrington T, et al. Protease resistance of food proteins: a mixed picture for predicting allergenicity but 
a useful tool for assessing exposure. Clin Transl Allergy. (2018) 8:1-12. doi: 10.1186/s13601-018-0216-9

113. Gómez M, Martínez-naves E. The role of lipids in development of allergic responses. Immune Netw. (2017) 17:133-43. doi: 10.4110/in.2017.17.3.133

114. Foo ACY, Thompson PM, Chen S, Jadi R, Lupo B, DeRose EF, et al. The mosquito protein AEG12 displays both cytolytic and antiviral properties via a common lipid transfer mechanism. Proc Natl Acad Sci USA. (2021) 118:e2019251118. doi: 10.1073/pnas.2019251118

115. Oeo-Santos C, Lopez-Rodriguez JC, Garcia-Mouton C, Segundo-Acosta PS, Juardo A, Moreno-Aguilar C, et al. Biophysical and biological impact on the structure and IgE- binding of the interaction of the olive pollen allergen Ole e 7 with lipids. Biochem Biophys Acta Biomembr. (2020) 1862:183258. doi: $10.1016 /$ j.bbamem.2020.183258

116. López-Rodríguez JC, Barderas R, Echaide M, Pérez-Gil J, Villalba M, Batanero E, et al. Surface activity as a crucial factor of the biological actions of Ole e 1, the main aeroallergen of olive tree (Olea europaea) pollen. Langmuir. (2016) 32:11055-62. doi: 10.1021/acs.langmuir.6b02831

117. Trompette A, Divanovic S, Visintin A, Blanchard C, Hegde RS, Madan R, et al. Allergenicity resulting from functional mimicry of a Toll-like receptor complex protein. Nature. (2009) 457:585-9. doi: 10.1038/nature07548

118. Roldán NG, Engel R, Düpow S, Jakob K, Koops F, Orinska Z, et al. Lipid mediators from timothy grass pollen contribute to the effector phase of allergy and prime dendritic cells for glycolipid presentation. Front Immunol. (2019) 10:974. doi: 10.3389/fimmu.2019.00974

119. Luo C, Guo Y, Li Z, Ahmed I, Pramod SN, Gao X, et al. Lipid emulsion enhances fish allergen parvalbumin's resistance to in vitro digestion and IgG/IgE binding capacity. Food Chem. (2020) 302:125333. doi: 10.1016/j.foodchem.2019.125333

120. Angelina A, Sirvent S, Palladino C, Vereda A, Cuesta-Herranz J, Eiwegger T, et al. The lipid interaction capacity of Sin a 2 and Ara h 1, major mustard and peanut allergens of the cupin superfamily, endorses allergenicity. Allergy Eur J Allergy Clin Immunol. (2016) 71:1284-94. doi: 10.1111/all.12887

121. Mueller GA, Pedersen LC, Lih FB, Glesner J, Moon AF, Chapman MD, et al. The novel structure of the cockroach allergen Bla g 1 has implications for allergenicity and exposure assessment. J Allergy Clin Immunol. (2013) 132:1420-6. doi: 10.1016/j.jaci.2013.06.014

122. Foo ACY, Thompson PM, Perera L, Arora S, DeRose EF, Williams J, et al. Hydrophobic ligands influence the structure, stability, and processing of the major cockroach allergen Bla g 1. Sci Rep. (2019) 9:18294. doi: 10.1038/s41598-019-54689-8

123. Soh WT, Aglas L, Mueller GA, Gilles S, Weiss R, Scheiblhofer S, et al. Multiple roles of Bet $\mathrm{v} 1$ ligands in allergen stabilization and modulation of endosomal protease activity. Allergy Eur J Allergy Clin Immunol. (2019) 74:2382-93. doi: $10.1111 /$ all.13948

124. Seutter von Loetzen C, Hoffmann T, Hartl MJ, Schweimer K, Schwab $\mathrm{W}$, Rösch P, et al. Secret of the major birch pollen allergen Bet $\mathrm{v} 1$ : identification of the physiological ligand. Biochem J. (2014) 457:379-90. doi: 10.1042/BJ20130413

125. Marković-Housley Z, Degano M, Lamba D, Von Roepenack-Lahaye E, Clemens S, Susani M, et al. Crystal structure of a hypoallergenic isoform of the major birch pollen allergen Bet $\mathrm{v} 1$ and its likely biological function as a plant steroid carrier. J Mol Biol. (2003) 325:123-33. doi: 10.1016/S0022-2836(02)01197-X

126. Hall J. A simple model for determining affinity from irreversible thermal shifts. Protein Sci. (2019) 28:1880-7. doi: 10.1002/pro.3701

127. Finkina EI, Melnikova DN, Bogdanov I V., Matveevskaya NS, Ignatova AA, Toropygin IY, et al. Impact of different lipid ligands on the stability and igebinding capacity of the lentil allergen len c 3. Biomolecules. (2020) 10:1668. doi: 10.3390/biom 10121668

128. Vassilopoulou E, Rigby N, Moreno FJ, Zuidmeer L, Akkerdaas J, Tassios I, et al. Effect of in vitro gastric and duodenal digestion on the allergenicity of grape lipid transfer protein. J Allergy Clin Immunol. (2006) 118:473-80. doi: 10.1016/j.jaci.2006.04.057

129. Abdullah SU, Alexeev Y, Johnson PE, Rigby NM, MacKie AR, Dhaliwal $\mathrm{B}$, et al. Ligand binding to an allergenic lipid transfer protein enhances conformational flexibility resulting in an increase in susceptibility to gastroduodenal proteolysis. Sci Rep. (2016) 6:30279. doi: 10.1038/srep30279
130. Satitsuksanoa P, Kennedy M, Gilis D, Le Mignon M, Suratannon N, Soh WT, et al. The minor house dust mite allergen Der p 13 is a fatty acid-binding protein and an activator of a TLR2-mediated innate immune response. Allergy Eur J Allergy Clin Immunol. (2016) 71:1425-34. doi: $10.1111 /$ all. 12899

131. Smole U, Gour N, Phelan J, Hofer G, Köhler C, Kratzer B, et al. Serum amyloid $\mathrm{A}$ is a soluble pattern recognition receptor that drives type 2 immunity. Nat Immunol. (2020) 21:756-65. doi: 10.1038/s41590-020-0698-1

132. Cayrol C, Girard JP. The IL-1-like cytokine IL-33 is inactivated after maturation by caspase-1. Proc Natl Acad Sci USA. (2009) 106:9021-6. doi: 10.1073/pnas.0812690106

133. Mogensen JE, Ferreras M, Wimmer R, Petersen S V., Enghild JJ, Otzen DE. The major allergen from birch tree pollen, Bet $\mathrm{v} 1$, binds and permeabilizes membranes. Biochemistry. (2007) 46:3356-65. doi: 10.1021/bi062058h

134. Thomas WR, Hales BJ, Smith WA. Structural biology of allergens. Curr Allergy Asthma Rep. (2005) 5:388-93. doi: 10.1007/s11882-005-0012-1

135. Chapman MD, Wünschmann S, Pomés A. Proteases as Th2 adjuvants. Curr Allergy Asthma Rep. (2007) 7:363-7. doi: 10.1007/s11882-007-0055-6

136. Dietz CJ, Sun H, Yao WC, Citardi MJ, Corry DB, Luong AU. Aspergillus fumigatus induction of IL-33 expression in chronic rhinosinusitis is PAR2dependent. Laryngoscope. (2019) 129:2230-5. doi: 10.1002/lary.28000

137. Kale SL, Arora N. Per a 10 activates human derived epithelial cell line in a protease dependent manner via PAR-2. Immunobiology. (2015) 220:525-32. doi: 10.1016/j.imbio.2014.10.018

138. Kondo S, Helin H, Shichijo M, Bacon KB. Cockroach allergen extract stimulates protease-activated receptor-2 (PAR-2) expressed in mouse lung fibroblast. Inflamm Res. (2004) 53:489-96. doi: 10.1007/s00011-004-1287-8

139. Jeong SK, Kim HJ, Youm JK, Ahn SK, Choi EH, Sohn MH, et al. Mite and cockroach allergens activate protease-activated receptor 2 and delay epidermal permeability barrier recovery. J Invest Dermatol. (2008) 128:19309. doi: $10.1038 /$ jid.2008.13

140. Lefrançais E, Roga S, Gautier V, Gonzalez-de-Peredo A, Monsarrat B, Girard JP, et al. IL-33 is processed into mature bioactive forms by neutrophil elastase and cathepsin G. Proc Natl Acad Sci USA. (2012) 109:1673-8. doi: 10.1073/pnas.1115884109

141. Cayrol C, Duval A, Schmitt P, Roga S, Camus M, Stella A, et al. Environmental allergens induce allergic inflammation through proteolytic maturation of IL-33. Nat Immunol. (2018) 19:375-85. doi: 10.1038/s41590-018-0067-5

142. Scott IC, Majithiya JB, Sanden C, Thornton P, Sanders PN, Moore T, et al. Interleukin- 33 is activated by allergen- and necrosis-associated proteolytic activities to regulate its alarmin activity during epithelial damage. Sci Rep. (2018) 8:3363. doi: 10.1038/s41598-018-21589-2

143. Randall TA, London RE, Fitzgerald MC, Mueller GA. Proteases of Dermatophagoides pteronyssinus. Int J Mol Sci. (2017) 18:1204. doi: 10.3390/ijms18061204

144. Grozdanovic MM, Cavić M, Nešić A, Andjelković U, Akbari P, Smit JJ, et al. Kiwifruit cysteine protease actinidin compromises the intestinal barrier by disrupting tight junctions. Biochim Biophys Acta Gen Subj. (2016) 1860:51626. doi: 10.1016/j.bbagen.2015.12.005

145. Kale SL, Agrawal K, Gaur SN, Arora N. Cockroach protease allergen induces allergic airway inflammation via epithelial cell activation. Sci Rep. (2017) 7:4234. doi: 10.1038/srep42341

146. Wan H, Winton HL, Soeller C, Tovey ER, Gruenert DC, Thompson PJ, et al. Der $\mathrm{p} 1$ facilitates transepithelial allergen delivery by disruption of tight junctions. J Clin Invest. (1999) 104:123-33. doi: 10.1172/JCI5844

147. Henriquez OA, Beste K Den, Hoddeson EK, Parkos CA, Nusrat A, Wise SK. House dust mite allergen Der p 1 effects on sinonasal epithelial tight junctions. Int Forum Allergy Rhinol. (2013) 3:630-5. doi: 10.1002/alr.21168

148. Post S, Nawijn MC, Jonker MR, Kliphuis N, Van Den Berge M, Van Oosterhout AJM, et al. House dust mite-induced calcium signaling instigates epithelial barrier dysfunction and CCL20 production. Allergy Eur J Allergy Clin Immunol. (2013) 68:1117-25. doi: 10.1111/all.12202

149. Mauri M, Elli T, Caviglia G, Uboldi G, Azzi M. RAWGraphs: a visualisation platform to create open outputs. In: Proceedings of the 12th Biannual Conference on Italian SIGCHI Chapter. Cagliari (2017). p. 1-5. doi: $10.1145 / 3125571.3125585$ 
150. da Silva ES, Aglas L, Pinheiro CS, de Andrade Belitardo EMM, Silveira EF, Huber S, et al. A hybrid of two major Blomia tropicalis allergens as an allergy vaccine candidate. Clin Exp Allergy. (2020) 50:835-47. doi: $10.1111 /$ cea. 13611

151. Campana R, Vrtala S, Maderegger B, Dall'Antonia Y, Zafred D, Blatt $\mathrm{K}$, et al. Altered IgE epitope presentation: a model for hypoallergenic activity revealed for Bet v 1 trimer. Mol Immunol. (2011) 48:431-41. doi: 10.1016/j.molimm.2010.09.016

152. Vrtala S, Fohr M, Campana R, Baumgartner C, Valent P, Valenta R. Genetic engineering of trimers of hypoallergenic fragments of the major birch pollen allergen, Bet v 1, for allergy vaccination. Vaccine. (2011) 29:2140-8. doi: 10.1016/j.vaccine.2010.12.080

153. Reisinger J, Horak F, Pauli G, Van Hage M, Cromwell O, König F, et al. Allergen-specific nasal IgG antibodies induced by vaccination with genetically modified allergens are associated with reduced nasal allergen sensitivity. J Allergy Clin Immunol. (2005) 116:347-54. doi: 10.1016/j.jaci.2005.04.003

154. Schülke S, Kuttich K, Wolfheimer S, Duschek N, Wangorsch A, Reuter A, et al. Conjugation of wildtype and hypoallergenic mugwort allergen Art $v 1$ to flagellin induces IL-10-DC and suppresses allergen-specific TH2-responses in vivo. Sci Rep. (2017) 7:11782. doi: 10.1038/s41598-017-11972-w

155. Banerjee S, Weber M, Blatt K, Swoboda I, Focke-Tejkl M, Valent $\mathrm{P}$, et al. Conversion of Der p 23, a new major house dust mite allergen, into a hypoallergenic vaccine. J Immunol. (2014) 192:4867-75. doi: 10.4049/jimmunol.1400064

156. Aglas L, Bethanis A, Chrusciel P, Stolz F, Gruen M, Jaakkola UM, et al. In vivo induction of functional inhibitory IgG antibodies by a hypoallergenic Bet v 1 variant. Front Immunol. (2020) 11:2118. doi: 10.3389/fimmu.2020.02118

157. Aglas L, Gilles S, Bauer R, Huber S, Araujo GR, Mueller G, et al. Context matters: $\mathrm{TH} 2$ polarization resulting from pollen composition and not from protein-intrinsic allergenicity. J Allergy Clin Immunol. (2018) 142:984-7.e6. doi: 10.1016/j.jaci.2018.05.004
158. Tordesillas L, Cubells-Baeza N, Gómez-Casado C, Berin C, Esteban V, Barcik W, et al. Mechanisms underlying induction of allergic sensitization by Pru p 3. Clin Exp Allergy. (2017) 47:1398-408. doi: 10.1111/cea. 12962

159. Dearman RJ, Alcocer MJC, Kimber I. Influence of plant lipids on immune responses in mice to the major Brazil nut allergen Ber e 1. Clin Exp Allergy. (2007) 37:582-91. doi: 10.1111/j.1365-2222.2007. 02689.x

160. Aalberse RC, Crameri R. IgE-binding epitopes: a reappraisal. Allergy Eur J Allergy Clin Immunol. (2011) 66:1261-74. doi: $10.1111 / j .1398-9995.2011 .02656 . x$

161. Matricardi PM, Kleine-Tebbe J, Hoffmann HJ, Valenta R, Hilger C, Hofmaier $\mathrm{S}$, et al. EAACI molecular allergology user's guide. Pediatr Allergy Immunol. (2016) 27(Suppl. 23):1-250. doi: 10.1111/pai.12563

Conflict of Interest: The authors declare that the research was conducted in the absence of any commercial or financial relationships that could be construed as a potential conflict of interest.

Publisher's Note: All claims expressed in this article are solely those of the authors and do not necessarily represent those of their affiliated organizations, or those of the publisher, the editors and the reviewers. Any product that may be evaluated in this article, or claim that may be made by its manufacturer, is not guaranteed or endorsed by the publisher.

Copyright (c) 2021 Foo and Mueller. This is an open-access article distributed under the terms of the Creative Commons Attribution License (CC BY). The use, distribution or reproduction in other forums is permitted, provided the original author(s) and the copyright owner(s) are credited and that the original publication in this journal is cited, in accordance with accepted academic practice. No use, distribution or reproduction is permitted which does not comply with these terms. 